\title{
Gaseous surface hardening of Ti-6Al-4V fabricated by selective laser melting
}

\author{
Valente, Emilie H.; Jellesen, Morten S.; Somers, Marcel A. J.; Christiansen, Thomas L.
}

Published in:

Surface and Coatings Technology

Link to article, DOI:

10.1016/j.surfcoat.2019.125278

Publication date:

2020

Document Version

Peer reviewed version

Link back to DTU Orbit

Citation (APA):

Valente, E. H., Jellesen, M. S., Somers, M. A. J., \& Christiansen, T. L. (2020). Gaseous surface hardening of Ti6Al-4V fabricated by selective laser melting. Surface and Coatings Technology, 383, [125278].

https://doi.org/10.1016/j.surfcoat.2019.125278

\section{General rights}

Copyright and moral rights for the publications made accessible in the public portal are retained by the authors and/or other copyright owners and it is a condition of accessing publications that users recognise and abide by the legal requirements associated with these rights.

- Users may download and print one copy of any publication from the public portal for the purpose of private study or research.

- You may not further distribute the material or use it for any profit-making activity or commercial gain

- You may freely distribute the URL identifying the publication in the public portal 


\title{
Gaseous surface hardening of Ti-6Al-4V fabricated by selective laser melting
}

\author{
Emilie H. Valente, Morten S. Jellesen, Marcel A. J. Somers, Thomas L. \\ Christiansen \\ Technical University of Denmark, Department of Mechanical Engineering, Produktionstorvet \\ b.425, 2800 Kgs.Lyngby,Denmark,.emhval@mek.dtu.dk,msj@mek.dtu.dk,somers@mek.dtu.dk, \\ tch@mek.dtu.dk
}

\author{
Corresponding author: \\ Emilie Hørdum Valente \\ Telephone : +4540381671 \\ Fax : +4545251961 \\ e-mail : emhval@mek.dtu.dk \\ Postal address: \\ Danmarks Tekniske Universitet \\ Produktionstorvet \\ Bygning 425, rum 129 \\ DK-2800 Kgs. Lyngby \\ Denmark
}

\begin{abstract}
The present work investigates the response of different gaseous thermochemical treatments on selective laser melted (SLM) Ti-6Al-4V. The resulting microstructures after thermochemical treatment were investigated with X-ray diffraction, light optical microscopy, scanning electron microscopy and Vickers-microhardness indentation. Nitriding, performed at $1000-1050{ }^{\circ} \mathrm{C}$ resulted in a diffusion zone of nitrogen in solid solution and surface compound layers consisting of $\operatorname{TiN}$ (and $\mathrm{Ti}_{2} \mathrm{~N}$ at $1000{ }^{\circ} \mathrm{C}$ ). Below the compound layer Al-enrichment of the $\alpha$-zone was observed. Carbo-oxidising in a $\mathrm{CO}$ atmosphere at $1000-1050{ }^{\circ} \mathrm{C}$ resulted in deep diffusion zones and thick compound layers of the ternary compound $\mathrm{TiC}_{1-\mathrm{x}} \mathrm{O}_{\mathrm{x}}$. Both surface hardness and
\end{abstract}


layer depth were found to increase with temperature and treatment time. Chemically controlled carbo-oxidising, applying the gas redox system $\mathrm{CO}-\mathrm{CO}_{2}$, was performed at temperatures in the range $850-1050{ }^{\circ} \mathrm{C}$, resulting in carbo-oxides and formation of oxides with increasing Ti:O ratio with increasing temperatures (rutile and Magnéli phases). Nitriding followed by (carbo)oxidising treatment resulted in higher surface hardness owing to the formation of mixed interstitial compounds $\mathrm{TiC}_{1-\mathrm{x}-\mathrm{y}} \mathrm{N}_{\mathrm{x}} \mathrm{O}_{\mathrm{y}}$ in the compound layer. The compound layer grew into the Al-rich zone as elongated structures.

The improvement of wear by nitriding, carbo-oxidising and duplex nitriding/ (carbo-)oxidising on SLM Ti-6Al-4V was evaluated by dry sliding wear testing. Lowering of the wear volume by up to a factor of 450 compared to an annealed reference sample was realised. Carbo-oxidising in $\mathrm{CO}$ at $1000{ }^{\circ} \mathrm{C}$ offered the best wear resistance and resulted in a lowering of the friction coefficient, averaging $\mu=0.22$, compared to $\mu=0.45$ for an annealed reference sample.

\section{Keywords}

Surface hardening, Ti-6Al-4V, selective laser melting, additive manufacturing, microstructure, wear 


\section{Introduction}

Near-net-shape and low-waste processing of metals additive manufacturing (AM) has spurred a renewed interest in titanium-based materials; the "work horse" titanium alloy Ti-6Al-4V has become the most investigated alloy for AM.[1] Hitherto, the high materials cost and limited forming abilities of titanium have made it too costly for a large number of applications where its properties, such as high strength-to-weight ratio and excellent corrosion resistance, are otherwise desired. AM with its high geometrical freedom, significant materials savings (low buy-to-fly ratio) and large cost savings now opens up new markets for titanium.[2] Unfortunately, the tribological properties of titanium are often inadequate in applications where the material is exposed to friction and wear. Hence, titanium will require surface engineering in order to improve the tribological properties.[3]

Surface engineering of titanium and its alloys can entail several different methods, such as CVD, PVD, electroplating, thermal oxidising, gas nitriding, gas carburising, plasma nitriding and pack carburising. Reviews of the state of the art of surface engineering of titanium can be found in the literature $[3,4]$. In gaseous thermochemical treatment, the component is heated in a reactive gaseous atmosphere to enable incorporation of, say, carbon, oxygen or nitrogen into the surface of the material. Depending on the specific nature of the process, this results in the formation of a diffusion zone where the interstitial elements are dissolved in (expanded) $\alpha$-titanium, and formation of a surface compound layer. Classically, gaseous nitriding has proven useful for titanium, due to a high hardness of the formed surface compounds $\operatorname{TiN}$ and $\mathrm{Ti}_{2} \mathrm{~N}$, combined with a substantial solid solubility of nitrogen in the $\alpha$-phase. Hence, a gradual transition from the hard surface compound layer to the softer bulk is obtained. Oxygen has a very high solid solubility in the $\alpha$-phase and is an effective strengthening element similar to nitrogen, but it is difficult to avoid formation of surface oxides, viz. rutile $\mathrm{TiO}_{2}$. Although oxides can provide excellent corrosion 
resistance, provided that they are present as an adhering layer, they are brittle, not as hard as nitrides and can be porous. Moreover, titanium oxide layers suffer from spallation if they become too thick. This can be avoided by boost oxidation and subsequent diffusion, developed by Dong et al., enabling deep hardening without the formation of a thick oxide layer, because the oxide is consumed in the diffusion step.[5] On the other hand, carbon forms an extremely hard compound TiC, but due to the low solid solubility of carbon in the $\alpha$-phase, the diffusion zone underneath has no load bearing capacity and there is a risk for egg-shell effect. Additionally, formation of TiC is difficult to achieve as a pure phase in gaseous systems and requires very high temperatures.

Recently the combination of dissolving (at least) two interstitial species in titanium has gained attention, with Fedirko et al. [6] highlighting the special chemical, physical and mechanical properties of ternary Ti-O-N-C compounds. Generally, more favourable properties can be obtained with ternary compounds than with the binary compounds.[6] Yaskiv et al. employed powder-pack carbo-oxidising of titanium, using graphite in an oxygen-containing medium. By varying temperature and oxygen partial pressure, the formation of $\mathrm{TiC}_{\mathrm{x}} \mathrm{O}_{1-\mathrm{x}}$ with various compositions (i.e. various x values) was achieved. An applied pressure of $3 \mathrm{~Pa}$ yielded the highest surface hardness of $1670 \mathrm{HV}$ corresponding to a compound composition of $\mathrm{TiC}_{0.63} \mathrm{O}_{0.37}$, as determined by X-ray diffraction (XRD).[7] Gammeltoft-Hansen et al. [8] successfully carbo-oxidised both commercially pure titanium (Grade 2) and Ti-6Al-4V in a gaseous atmosphere containing only carbon and oxygen, confirming the formation of $\mathrm{TiC}_{\mathrm{x}} \mathrm{O}_{1-\mathrm{x}}$ by $\mathrm{XRD}$. The obtained hardness was approximately $2200 \mathrm{HV}$ for the compound phase and $1500 \mathrm{HV}$ in the diffusion zone for Ti grade 2.[8] Very recently, it has also been shown that three interstitial elements (nitrogen, carbon and oxygen) can be incorporated into the surface of titanium grade 2 , resulting in a high total interstitial solid solubility.[9]

A few examples of surface engineering of Ti-based AM components have been published. Franz et al. performed gas nitriding of a lightweight knife for divers, fabricated by selective laser melting 
(SLM).[10] Gas carburising was used by Kim et al. to reduce the coefficient of friction of pure titanium fabricated by electron beam melting (EBM) by forming TiC precipitates in the surface region.[11] This increased the hardness to $420 \mathrm{HV}$ near the surface and resulted in a lower friction coefficient of the carburised specimen. Kao et al. showed improved corrosion resistance, wear resistance and biocompatibility by employing nitriding and subsequent diamond-like carbon (DLC) coating to SLM fabricated Ti-6Al-4V.[12] The study introduced strategies for surface engineering of implants, although the sputtering process used for the DLC coating gets complicated when the geometry moves from flat test specimens to actual implants.

All purely gaseous thermochemical treatments have the advantage of being independent of geometry and producing a layer on all surfaces in contact with the gas atmosphere. Hence, these processes are an obvious choice for surface engineering of components with the high geometrical complexity enabled by AM. Combining the lower cost of AM Ti-6Al-4V parts and gaseous surface hardening can potentially provide unique properties and enable the use of additively manufactured titanium in a much wider range of applications.

The present study investigates gaseous thermochemical treatments of Ti-6Al-4V parts fabricated by SLM. Specifically, nitriding, two different types of carbo-oxidising and combinations of nitriding and (carbo-)oxidising will be addressed. Additionally, the tribological performances of the different treatments are investigated. Deliberately, SLM samples with a relatively high degree of porosity $(\sim 3.5 \%)$ were used for the study, making it possible to investigate the effect of porosity on the thermochemical treatments.

Treatments were performed on both as-built and mechanically ground specimens, thus reflecting different surface conditions. 


\section{Experimental procedure}

\subsection{Materials and SLM process}

Cuboids of $10 \times 10 \times 3 \mathrm{~mm}^{3}$ were manufactured by the Danish Technological Institute using a MCP Realizer SLM 250 (from 2006) and grade 5 titanium powder from SLM Solutions. The composition of the powder, as specified by the supplier, was: $6.34 \mathrm{wt} \% \mathrm{Al}, 4.1 \mathrm{wt} . \% \mathrm{~V}, 0.183$ wt.\% Fe, 0.140 wt. $\%$ O, 0.005 wt. $\%$ C, 0.007 wt. $\%$ N, 0.0020 wt.\% H; the powder size was in the range 20-63 $\mu \mathrm{m}$. The specimens were built vertically on support structures using the following scanning strategy: Line Scanning using antiparallel stripes with $90^{\circ}$ rotation between consecutive layers. The used processing parameters were: power $100 \mathrm{~W}$, exposure time $180 \mu$ s, scan speed 800 $\mathrm{mm} \mathrm{s}^{-1}$, hatch distance $80 \mu \mathrm{m}$ and layer thickness $50 \mu \mathrm{m}$, giving an energy density of $56 \mathrm{~J} \mathrm{~mm}^{-3}$.

\subsection{CT-imaging}

X-ray computed tomography of an as-built specimen was performed with a ZEISS Xradia Versa XRM-410 3D X-ray using a $100 \mathrm{kV}$ voltage, $10 \mathrm{~W}$ power, Large Field of View objective, HE1 filter and 8 seconds count time per image. 3D imaging was done using the Avizo 9 software.

\subsection{Thermochemical treatments}

\subsubsection{Nitriding}

Nitriding of Ti-6Al-4V was carried out in a horizontal Kanthal-tube furnace using $\mathrm{N}_{2}$ gas (purity $99.999 \%$ ) at atmospheric pressure. The treatments were performed at $1000^{\circ} \mathrm{C}$ for 16 hours and $1050{ }^{\circ} \mathrm{C}$ for 2 hours. A cooling rate averaging $94^{\circ} \mathrm{C} / \mathrm{min}$ from $1050{ }^{\circ} \mathrm{C}$ to $500{ }^{\circ} \mathrm{C}$ was measured for the applied cooling. The nitriding process was performed both directly on as-built surfaces and on ground surfaces. Samples for wear testing (see below) were ground until P4000 paper prior to nitriding. 


\subsubsection{Carbo-oxidising in $\mathrm{CO}$}

Carbo-oxidising was performed on samples ground to P4000 paper. The treatments were performed for 16 hours at $1000{ }^{\circ} \mathrm{C}$ or $1050{ }^{\circ} \mathrm{C}$ in a Netzsch simultaneous thermal analyser STA449. The applied gas flow was $64.4 \mathrm{ml} / \mathrm{min} \mathrm{CO}$ (linear flow rate of $769 \mathrm{~cm} / \mathrm{h}$ ) and $7 \mathrm{ml} / \mathrm{min}$ Ar. A horizontal fused quartz tube furnace was used for a $2 \mathrm{~h}$ treatment at $1050{ }^{\circ} \mathrm{C}$ applying a $\mathrm{CO}$ flow of $100 \mathrm{ml} / \mathrm{min}$ (linear flow rate of $138 \mathrm{~cm} / \mathrm{h}$ ). Since the treatments were performed with CO as the only "reactive" gas species, the oxygen partial pressure and carbon activity are - strictly speaking - not controlled/defined. However, $\mathrm{CO}$ will provide a very low partial pressure of oxygen and a high carburising activity; see also section below.

\subsubsection{Chemically controlled carbo-oxidising}

Chemically controlled carbo-oxidising was performed on as-built SLM samples in the Netzsch thermal analyser STA 449C at atmospheric pressure in a gas flow consisting of $64.4 \mathrm{ml} / \mathrm{min} \mathrm{CO}$, $1 \mathrm{ml} / \mathrm{min} \mathrm{CO}_{2}$ and $7 \mathrm{ml} / \mathrm{min}$ Ar. The redox system $\mathrm{CO}-\mathrm{CO}_{2}$ ensures a chemically controlled partial pressure of oxygen and carbon activity.[13] The treatment time was 16 hours at the temperatures $850,925,1000$ and $1050^{\circ} \mathrm{C}$. The oxygen partial pressure $\left(\mathrm{pO}_{2}\right)$ and carbon activity $(\mathrm{ac})$ for the gas mixture at the applied temperatures are given in Table 1.

Table 1: Treatment conditions for the chemically controlled carbo-oxidising treatments.

\begin{tabular}{ccccc} 
Temperature $\left({ }^{\circ} \mathrm{C}\right)$ & 850 & 925 & 1000 & 1050 \\
\hline Oxygen partial pressure, $\mathrm{pO}_{2}(\mathrm{~atm})$ & $1.5 \cdot 10^{-21}$ & $6.6 \cdot 10^{-20}$ & $1.9 \cdot 10^{-18}$ & $1.4 \cdot 10^{-17}$ \\
Carbon activity, $\mathrm{ac}_{\mathrm{c}}$ & 3.87 & 1.23 & 0.45 & 0.24
\end{tabular}

A fifth carbo-oxidising treatment was performed at $913{ }^{\circ} \mathrm{C}$ for 3 hours, as this temperature and time correspond to a thermal anneal specified by AMS 4999 for SLM Ti-6Al-4V. 
Duplex treatment was performed by conducting chemically controlled carbo-oxidising of samples nitrided at $1050{ }^{\circ} \mathrm{C}$ for 2 hours. These treatments were performed both on samples nitrided in the as-built and the ground condition; the former was used for microstructural investigations, and the latter used for wear testing. The treatment was performed for 48 hours at $820^{\circ} \mathrm{C}$, in a horizontal $\mathrm{SiO}_{2}$ tube furnace, with furnace cooling, averaging $6^{\circ} \mathrm{C} / \mathrm{min}$. A gas with $\mathrm{pO}_{2}=4.910^{-22} \mathrm{~atm}$ and $\mathrm{a}_{\mathrm{c}}=5.39$ was used by employing a flow of $100 \mathrm{ml} \mathrm{CO} / \mathrm{min}$ and $2 \mathrm{ml} \mathrm{CO} / \mathrm{min}$ at $820^{\circ} \mathrm{C}$.

\subsection{Heat treatment}

For comparison with an $\alpha / \beta$ microstructure of comparable composition and density, but without surface hardening, a SLM fabricated sample was heat treated at $1050{ }^{\circ} \mathrm{C}$ for 1 hour in the Kanthaltube furnace in an argon (99.999\%) atmosphere. The sample was ground to P4000 after treatment, to remove the slight surface oxygen pick-up from the Ar atmosphere; this condition was also used for tribological investigations.

\subsection{Microstructural characterisation}

Phase analysis was performed on the surface of the samples by XRD using a Bruker D8 Discover, equipped with Mo K $\alpha$-radiation. X-ray diffractograms were collected in symmetrical $\theta-2 \theta$ scans using Bragg-Brentano focussing geometry with a stepsize of $0.005^{\circ}$ and a counting time per step ranging from 2-11 seconds, depending on the complexity of the XRD patterns. The $\mathrm{K}_{\alpha 2}$ contribution was stripped using the Bruker EVA software.

The surface roughness of the samples used for wear testing was measured by a Taylor Hobson Surftronic 25 surface roughmeter. 12 measurements were obtained on each sample, from which average surface roughness $\left(\mathrm{R}_{\mathrm{a}}\right)$ values were calculated.

In order to investigate the surface and bulk microstructures, cross sections parallel to the building direction were obtained by cutting and embedding. After mechanical grinding and polishing until 
$1 \mu \mathrm{m}$ diamond, the cross sections were polished with Struers' OP-S for 8 minutes, finishing with cleaning in water, followed by ethanol.

The hardness of the surface layers was determined by hardness indentations. Hardness depth profiles were determined using a FM-700 micro Vickers hardness tester, using 10 seconds dwell time and a load of $10 \mathrm{~g}$. The presented hardness-indentation results are an average of 3-4 profiles. Bulk hardness values are averages of $\sim 30$ measurements from the bulk part of the profiles.

The cross sections were carbon coated and investigated with scanning electron microscopy (SEM), using a PhenomWorld Phenom Pro with a 4-sector backscatter electron detector. The as-built specimen was also investigated with SEM after etching (10 s immersion in oxalic tinting reagent) to reveal/distinguish the martensite lath morphology.

For light optical microscopy (OLYMPUS GC41), the embedded samples were re-polished and etched by a $10 \mathrm{~s}$ immersion in oxalic tinting reagent consisting of $20 \mathrm{~g}$ oxalic acid, $10 \mathrm{ml} 10 \%$ hydrofluoric acid and $18 \mathrm{ml}$ distilled water.

\subsection{Tribological properties}

The tribological properties of the SLM fabricated Ti-6Al-4V after grinding and thermochemical treatment were investigated by reciprocating pin-on-disc wear testing on a CSM Tribometer, in accordance with guidelines stated in ASTM-99. The reciprocating wear conditions were $80^{\circ}$ of a circle with $3 \mathrm{~mm}$ radius, using a load of $5 \mathrm{~N}$ and a frequency of $1 \mathrm{~Hz}$, giving a max. sliding speed of $1.32 \mathrm{~cm} / \mathrm{s}$, for 5000 cycles, thus equalling an accumulated total sliding distance of $42 \mathrm{~m}$. The tests were performed using a ceramic $\mathrm{Al}_{2} \mathrm{O}_{3}$ ball as counterbody in dry sliding at ambient temperature and atmosphere (approx. $25^{\circ} \mathrm{C}$ and $60 \%$ relative humidity). Each specimen was tested twice. The friction coefficient was measured and collected by Tribo X software. The average friction coefficient was calculated for the full run, from which an overall average was calculated for each specimen. The specific wear volume was calculated from the wear track width, as 
measured on a Leica 125 stereo-microscope, and averaged for each specimen. A JEOL JSM-5900 SEM was used in both secondary and in backscatter mode to investigate the topological features and the composition of the wear tracks.

\section{Results and discussion}

\subsection{As-built condition}

The geometry of the as-built specimens is illustrated in Figure 1(a), with the CT-reconstruction in Figure 1(b) showing the rough surface of the as-built specimens. The microstructure of the as-built Ti-6Al-4V is mainly martensitic, as shown by the SEM image in Figure 1(d). Primary, secondary, tertiary and quartic acicular $\alpha^{\prime}$ martensite can be identified which is consistent with findings in the literature [14]. The fine martensitic microstructure formed in elongated prior $\beta$ grains is inherent to Ti-6Al-4V and the SLM process due to the high thermal gradients and epitaxial growth [15]. This hierarchical microstructure is a consequence of cyclic remelting and reheating to the $\beta$ region [14].

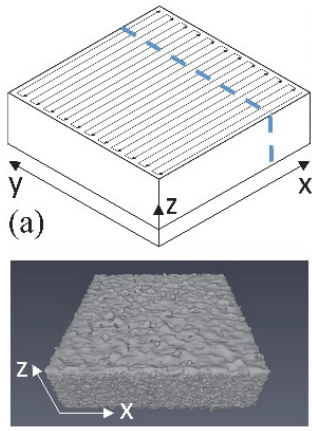

(b)
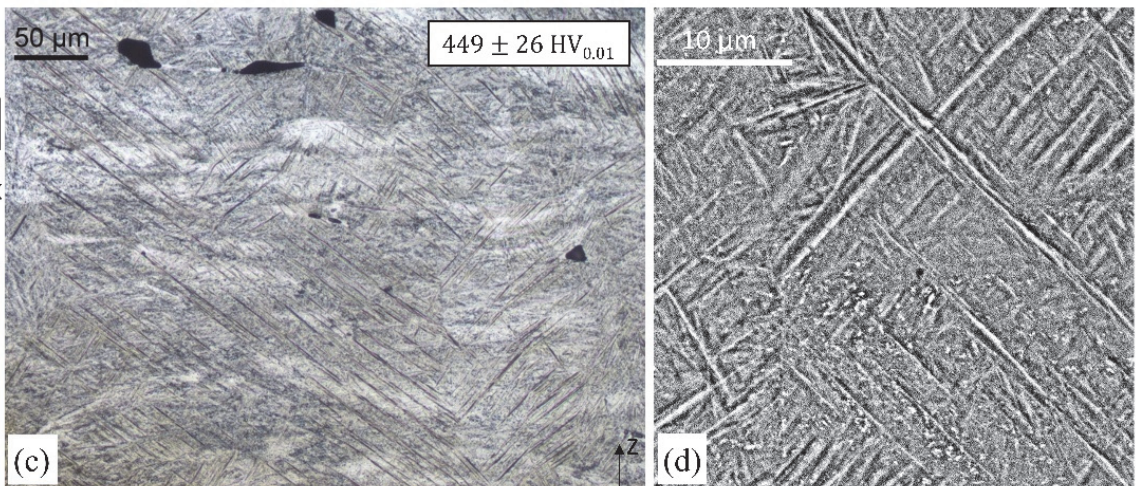

Figure 1: Illustration of sample geometry (a) showing build direction, z, and scan pattern (with 90-degree rotation between layers) and CT-reconstruction (b) showing a rough surface structure of an as-built sample. Light optical (c) and scanning electron (d) micrographs of the cross-section parallel to the build direction, showing the as-built martensitic microstructure of the SLM Ti-6Al-4V samples (etched with oxalic tinting reagent for 10 seconds). 
Large primary $\alpha^{\prime}$ laths are observed in the light optical micrograph in Figure 1(c); these are inclined approx. $\pm 45^{\circ}$ with respect to the build direction. The laths are constrained in the horizontal direction, because they have formed from elongated prior $\beta$ grains. The micrograph also reveals the presence of irregularly shaped pores, which are mostly incomplete fusion defects caused by unstable melt-pools due to non-optimum process parameters. The applied etching reagent reveals significant inhomogeneity in the material along the build direction, as seen especially by the brighter bands, caused by chemical, microstructural and/or dislocation density variations. Also, local variations in the thermal history will give rise to inhomogeneity. The average hardness of the SLM fabricated Ti-6Al-4V was $(449 \pm 26) \mathrm{HV}_{0.01}$, which is relatively high, but consistent with previous results for SLM fabricated Ti-6Al-4V[15,16]. The high standard deviation also reflects the inhomogeneity in the microstructure. Generally, higher hardness values are often observed for SLM martensitic structures together with high standard deviations due to inhomogeneity in the material.

\subsection{Nitriding and carbo-oxidising}

The X-ray diffractograms for the nitrided and the nitrided and subsequently carbo-oxidised samples are shown in Figure 2. For the sample nitrided at $1000{ }^{\circ} \mathrm{C}$ for 16 hours the diffractogram shows the formation of both TiN (rock salt Fm $3 \bar{m}$ structure) and $\varepsilon-\mathrm{Ti}_{2} \mathrm{~N}$. The peaks corresponding to the $\alpha-\mathrm{Ti}(\mathrm{HCP})$ phase are shifted slightly towards lower $2 \theta$ angles relative to an annealed (1050 $\left.{ }^{\circ} \mathrm{C}, 2 \mathrm{~h}\right)$ SLM Ti-6Al-4V reference sample; this confirms the formation of a zone of $\alpha$-Ti expanded by interstitially dissolved $\mathrm{N}$ atoms, $\alpha$-Ti( $(\mathrm{N})$. Nitriding at $1050^{\circ} \mathrm{C}$ for 2 hours resulted in the formation of TiN; no $\mathrm{Ti}_{2} \mathrm{~N}$ was identified. This implies that either $\mathrm{Ti}_{2} \mathrm{~N}$ is located deeper than the information depth probed by the X-rays or that $\mathrm{Ti}_{2} \mathrm{~N}$ does not form at $1050{ }^{\circ} \mathrm{C}$ (or subsequent cooling). As also nitrogen-expanded $\alpha$-Ti is identified with XRD, which is expected deeper in the case than $\mathrm{Ti}_{2} \mathrm{~N}$, it is concluded that the amount of $\mathrm{Ti}_{2} \mathrm{~N}$ is negligible (if present at all). After 
nitriding at $1050^{\circ} \mathrm{C}$ for $2 \mathrm{~h}$ followed by (carbo-)oxidising at $820^{\circ} \mathrm{C}$ for $48 \mathrm{~h}$ the $\mathrm{Ti}_{2} \mathrm{~N}$ phase was observed. Evidently, the lower temperature promotes the formation of $\mathrm{Ti}_{2} \mathrm{~N}$, which is in agreement with the Ti-N phase diagram. The oxidising environment also caused the formation of a thin oxide layer, most likely containing Magnéli type oxides with general formula $\mathrm{Ti}_{\mathrm{n}} \mathrm{O}_{2 \mathrm{n}-1}$; the peak positions mainly indicate the formation of $\mathrm{Ti}_{3} \mathrm{O}_{5}$ and $\mathrm{Ti}_{4} \mathrm{O}_{7}$. The introduction of oxygen/carbon gives rise to a broadening of the "TiN" peak to the low-angle side, suggesting the interstitial dissolution of C and/or $\mathrm{O}$ in addition to $\mathrm{N}$, leading to a compound of type $\mathrm{TiN}_{1-\mathrm{x}-\mathrm{y}} \mathrm{C}_{\mathrm{y}} \mathrm{O}_{\mathrm{x}}$.

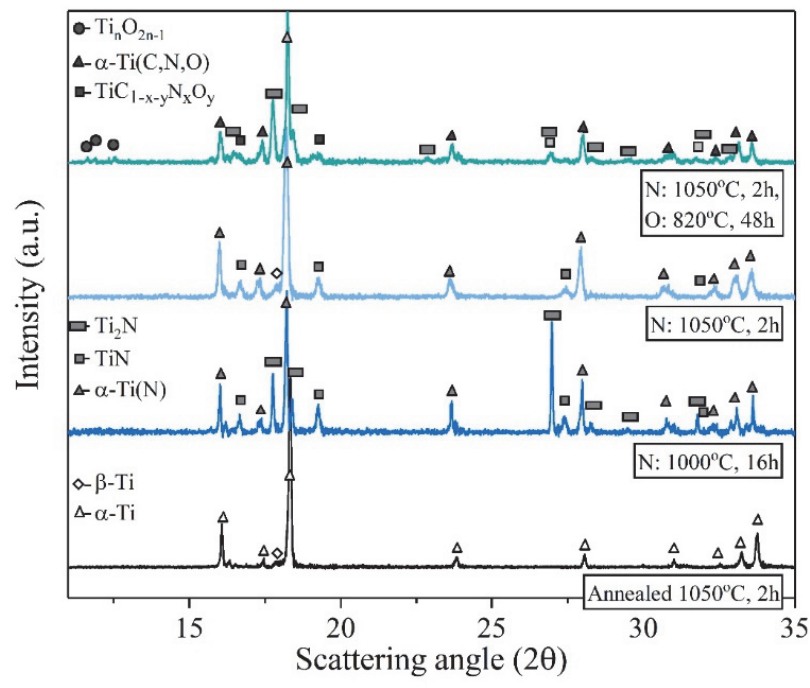

Figure 2: X-ray diffractograms of surface hardened SLM Ti-6Al-4V: Nitriding and nitriding followed by (carbo)oxidising treatments. A reference sample (annealed and polished) is also given.

Light-optical micrographs of the nitrided and duplex nitrided/(carbo-)oxidised samples are given in Figures 3(a) and 3(b), respectively. For the nitrided sample (Fig. 3(a)) the diffusion zone is clearly visible as a uniform zone below the compound layer where the microstructure is fully transformed into $\alpha-\operatorname{Ti}(\mathrm{N})$. There is a gradual transition from the uniform $\alpha-\operatorname{Ti}(\mathrm{N})$ zone into the bulk of the material where the fraction of nitrogen-stabilised "primary" $\alpha$ diminishes; this can be attributed to a gradual decrease in nitrogen content with depth. Growth of $\alpha$ grains in the elongated 
prior $\beta$ grains is observed, indicating that the treatment temperature has not been above the $\beta$ transus temperature, but reached the $\alpha+\beta$ two-phase region.

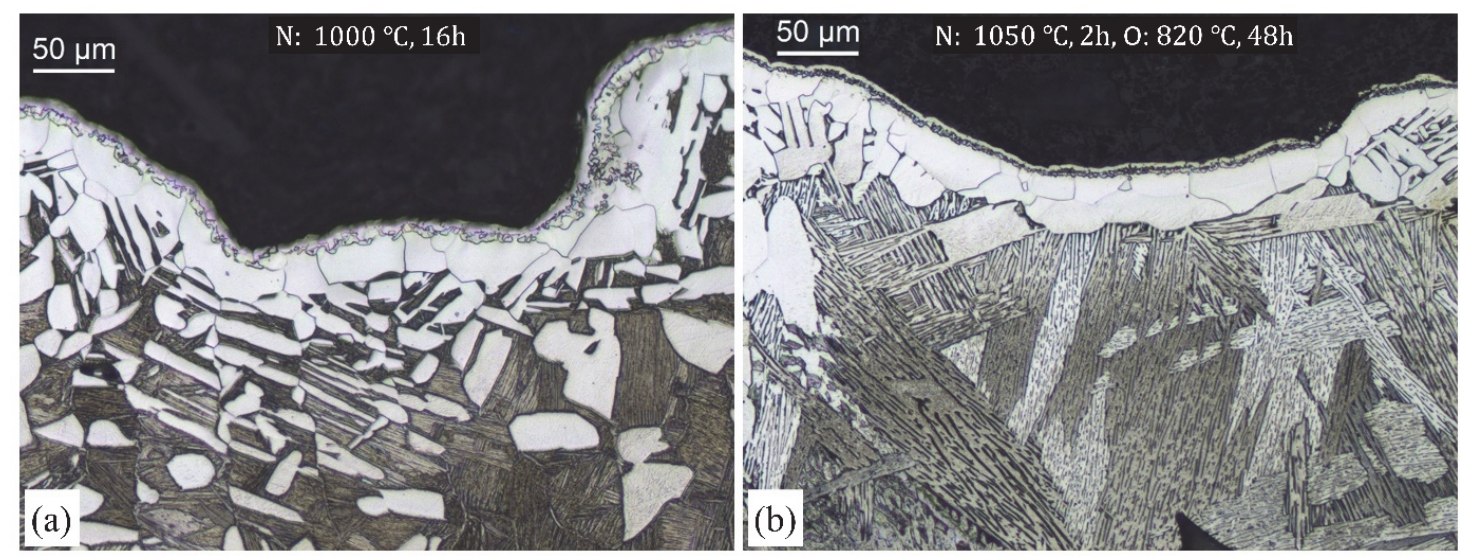

Figure 3: Light optical micrographs of the cross sections of (a) nitrided $\left(1000^{\circ} \mathrm{C}, 16 \mathrm{~h}\right)$ and (b) nitrided and oxidised (nitrided at $1050^{\circ} \mathrm{C}, 2 \mathrm{~h}$ and (carbo-)oxidised at $820^{\circ} \mathrm{C}, 48 \mathrm{~h}$ ) SLM Ti-6Al-4V samples (as-built surfaces). Etched with oxalic tinting reagent for 10 seconds.

The compound layer is relatively thin, has an irregular interface with the diffusion zone and appears to consist of two phases, i.e. TiN and $\mathrm{Ti}_{2} \mathrm{~N}$, as assessed with $\mathrm{XRD}$ (Figure 2).

Nitriding for $2 \mathrm{~h}$ at $1050^{\circ} \mathrm{C}$ followed by (carbo-)oxidising at $820^{\circ} \mathrm{C}$ (Figure $3(\mathrm{~b})$ ) reveals a uniform diffusion zone ( $\alpha$-Ti), which abruptly changes to the bulk (lamellar structure). This is characteristic of nitriding at a temperature above the $\beta$ transus (of the alloy), where the presence of nitrogen beyond the maximum nitrogen solubility in $\beta$ phase induces a transformation from $\beta$ to $\alpha$ and stabilises an $\alpha$ "case" atop the $\beta$ matrix. The compound layer has a different appearance than the compound layer obtained after nitriding at $1000^{\circ} \mathrm{C}$. The overall case appears deeper for the $16 \mathrm{~h}$ nitriding treatment at $1000^{\circ} \mathrm{C}$ than for the duplex treatment, where the nitriding treatment at 1050 ${ }^{\circ} \mathrm{C}$ lasted only $2 \mathrm{~h}$.

SEM micrographs of the hardened surface zone are given in Figure 4 and clearly reveal the morphology of the compound layers. A distinct $8 \mu \mathrm{m}$ thick compound layer is obtained after nitriding at $1000^{\circ} \mathrm{C}$ for $16 \mathrm{~h}$ (Figure $4(\mathrm{a})$ ). Below this layer, an approximately $8 \mu \mathrm{m}$ thick layer is 
observed (slightly darker). EDS (not shown) indicated a higher Al content in the second layer. This suggests that $\mathrm{Al}$ is expelled from the growing TiN during the nitriding. After nitriding at $1050{ }^{\circ} \mathrm{C}$ for $2 \mathrm{~h}$, the compound layer is significantly thinner (Figure $4(\mathrm{~b})$ ) than after $16 \mathrm{~h}$ at $1000^{\circ} \mathrm{C}$.
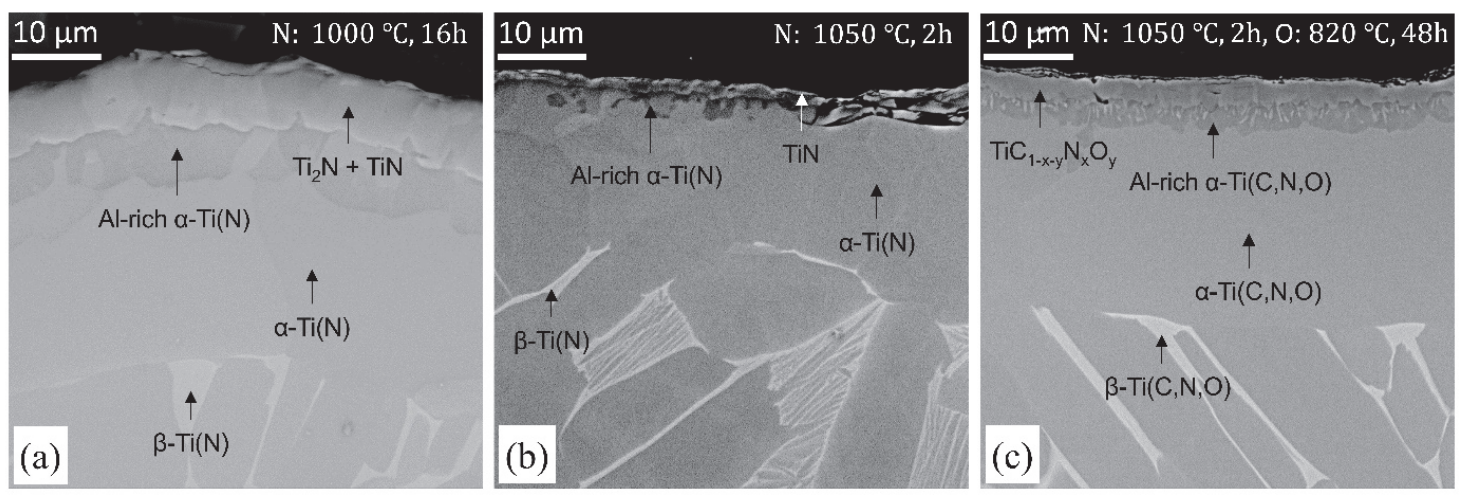

Figure 4: Scanning electron micrographs (back-scatter detector) of the cross-sections of (a) nitrided (1000 $\left.{ }^{\circ} \mathrm{C}, 16 \mathrm{~h}\right)$, (b) nitrided $\left(1050^{\circ} \mathrm{C}, 2 \mathrm{~h}\right)$ and (c) nitrided and (carbo-)oxidised (nitrided at $1050^{\circ} \mathrm{C}, 2 \mathrm{~h}$ and carbo-oxidised at 820 ${ }^{\circ} \mathrm{C}$, 48h) SLM Ti-6Al-4V samples (as-built surfaces). Polished with OP-S.

The "low temperature" carbo-oxidising step at $820^{\circ} \mathrm{C}$ for $48 \mathrm{~h}$ results in growth of both the compound layer and the diffusion zone (Fig. 4(c)). Growth of the diffusion zone can be attributed to i) redistribution by inward diffusion of nitrogen already present or ii) a higher amount of interstitials by addition of $\mathrm{C} / \mathrm{O}$. Growth of the compound layer during the carbo-oxidising treatment (comparing Figure 4(b-c)) is accompanied by growth of elongated structures protruding into the thicker Al-rich phase underneath.

The hardness depth profiles of the nitrided and the nitrided/(carbo-)oxidised samples are shown in Figure 5. All treatments significantly raised the surface hardness of the samples. The highest hardness was obtained after nitriding at $1000^{\circ} \mathrm{C}$ for 16 hours, yielding a value of $963 \pm 52 \mathrm{HV}_{0.01}$ at $20 \mu \mathrm{m}$ below the surface, closely followed by the duplex treatment reaching $944 \pm 32 \mathrm{HV}_{0.01}$. 


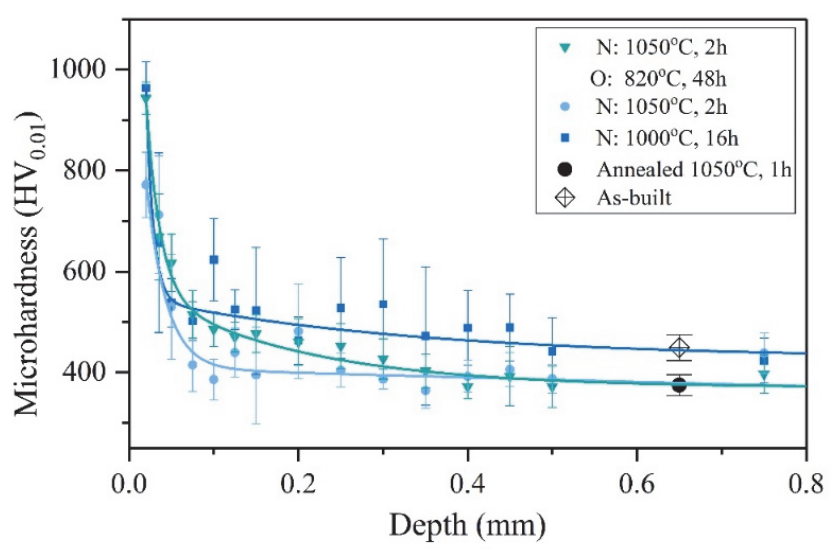

Figure 5: Micro-hardness profiles of nitrided and nitrided/(carbo-)oxidised SLM Ti-6Al-4V samples. The average micro-hardnesses of as-built and annealed reference samples are shown for comparison. The curves are drawn to guide the eye.

It should be emphasised that the maximum surface hardness is significantly higher, as TiN type compounds can exceed hardness values well over $2000 \mathrm{HV}$. Hardness values of this magnitude were not obtained in the present measurements, because of the limited thickness of the compound layer as compared to the size of the indenter. The values obtained at depths of $20 \mu \mathrm{m}$ reflect the hardness provided by interstitials in solid solution in $\alpha$-Ti. The hardness profile for the duplex treated sample appears smoother with narrower $95 \%$ confidence intervals than the other treatments. This is attributed to the more homogeneous microstructure, displaying a distinct and well-defined diffusion zone. The (carbo-)oxidising treatment after nitriding has resulted in an additional solid-solution hardening effect: the hardness after nitriding at $1050^{\circ} \mathrm{C}$ for 2 hours at the depth of $20 \mu \mathrm{m}$ was $772 \pm 65 \mathrm{HV}_{0.01}$, while it amounts to $944 \pm 32 \mathrm{HV}_{0.01}$ after the additional low temperature carbo-oxidising step.

\subsection{Carbo-oxidising in $\mathrm{CO}$}

Carbo-oxidising was performed on both ground and as-built SLM Ti-6Al-4V specimens for different temperatures and durations. The results on ground and as-built specimens are similar, and only the results of the ground specimens are shown. 
XRD, shown in Figure 6, confirms the formation of both a mixed interstitial compound and an expanded $\alpha$-Ti diffusion zone. The mixed interstitial compound has FCC peaks at positions inbetween those of the stoichiometric compounds $\mathrm{TiC}$ and $\mathrm{TiO}$ and is therefore interpreted as a titanium carbo-oxide: $\mathrm{TiC}_{1-\mathrm{x}} \mathrm{O}_{\mathrm{x}}$. The peak positions shifted slightly towards lower $2 \theta$ values with increasing temperature and treatment time. These peak shifts can be attributed to i) expansion of the FCC lattice, due to a higher (total) amount of interstitials (both $\mathrm{TiO}$ and $\mathrm{TiC}$ have a broad homogeneity range), ii) a higher carbon to oxygen ratio [17] or iii) a change in the stress state of the carbo-oxide compound. Obviously, the net result of the various effects is a shift to lower $2 \theta$ values. Micrographs of the carbo-oxide layers, shown in Figure 7, clearly show that the thickest compound layer was formed at $1050{ }^{\circ} \mathrm{C}$ for 16 hours (Figure $7(\mathrm{e}-\mathrm{f})$ ).

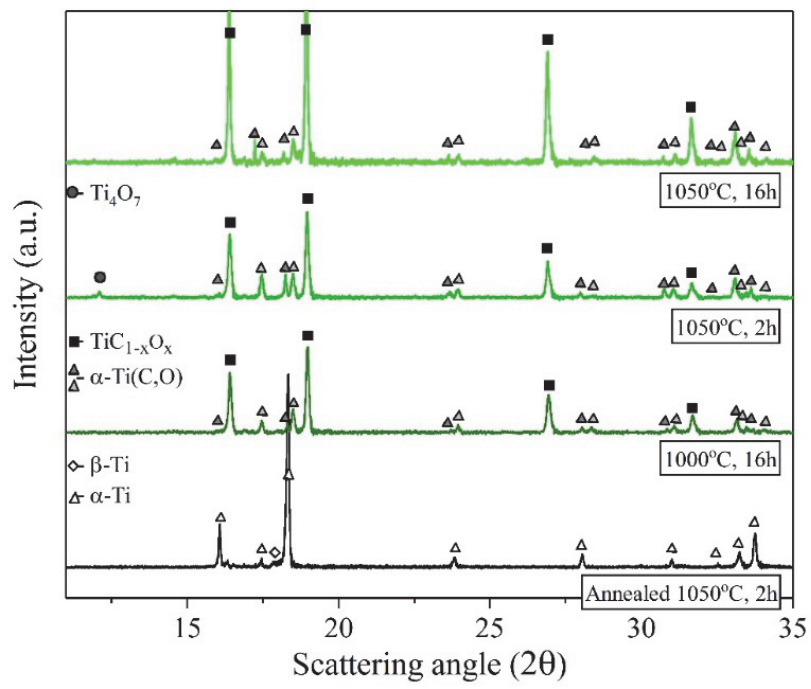

Figure 6: X-ray diffractograms of SLM Ti-6Al-4V following carbo-oxidising in pure CO flow, at different times and temperatures. As a reference, the diffractogram of an annealed and polished sample is added.

Separation or splitting of the $\alpha$-Ti phase peaks into two peaks is apparent in all diffractograms of the carbo-oxidised specimens. This is interpreted as two $\alpha$ phases with different chemical compositions. The change in composition can occur for the substitutional elements ( $\mathrm{Al}$ and $\mathrm{V}$ ) as well as for the interstitials. The peak shifted to lower $2 \theta$ angles most likely corresponds to 
expanded $\alpha-\mathrm{Ti}$, containing oxygen and carbon in solid solution, while the $\alpha$ peak positioned at higher $2 \theta$ angles most likely corresponds to an $\alpha$ phase with a higher aluminium content, as higher aluminium content leads to a reduction in lattice parameter.[18] It is noted that the $\alpha$-Ti phase with higher $2 \theta$ angles appears to have a lattice spacing lower than the interstitial-free reference material. Alternatively, this can be caused by tensile residual stresses in the $\alpha$ phase. It is not known whether the - presumably - Al-rich $\alpha$-Ti phase contains interstitials in solid solution.

The formation of $\mathrm{Ti}_{4} \mathrm{O}_{7}$ was identified for the $2 \mathrm{~h} 1050{ }^{\circ} \mathrm{C}$ treatment, indicating that either the process duration was too short to fully transform oxide into $\mathrm{TiC}_{\mathrm{x}} \mathrm{O}_{1-\mathrm{x}}[7]$, or that the effective oxygen partial pressure was slightly higher in the fused quartz tube furnace which would allow $\mathrm{TiC}_{\mathrm{x}} \mathrm{O}_{1-\mathrm{x}}$ to coexist with $\mathrm{Ti}_{4} \mathrm{O}_{7}$. If the latter applies, it emphasizes the importance of process control, which can be achieved by chemically controlled processing, were the oxygen partial pressure and carbon activity are controlled by adjusting the partial pressures of $\mathrm{CO}$ and $\mathrm{CO}_{2}$.

Light optical and SEM micrographs of cross sections of the carbo-oxidised specimens are given in Figure 7. The compound zone/layer appears uniform for all treatments; an approximately 40 $\mu \mathrm{m}$ thick zone develops on the $1000{ }^{\circ} \mathrm{C} / 16 \mathrm{~h}$ specimen (Fig. 7a) and a zone of approximately 30 $\mu \mathrm{m}$ is found for the $1050{ }^{\circ} \mathrm{C} / 2 \mathrm{~h}$ specimen (Fig. 7c). The $1050{ }^{\circ} \mathrm{C} / 16 \mathrm{~h}$ treatment (Fig. 7e) produces a compound zone of $70 \mu \mathrm{m}$. The carbo-oxide compound is continuous at the surface and appears dispersed in the remainder of the zone. This intertwined growth could be beneficial for adhesion of the compound zone. The phase present just below and mixed with the carbo-oxides (Figure 7(b), (d) and (f)) is rich in aluminium. Hence, it is identified as $\alpha$-Ti, consistent with XRD (cf. above). Evidently, Al does not reside in the carbo-oxides, and is redistributed while pushed ahead of the growing carbo-oxide phase, thereby augmenting the aluminium content in the surrounding $\alpha$ phase. Analogously, patches of $\beta$-phase are found just below the Al-rich $\alpha$-phase, as a consequence of redistributing vanadium ahead of the carbo-oxides and the Al-rich $\alpha$-phase. An enhanced $V$ content stabilizes $\beta$ phase. 

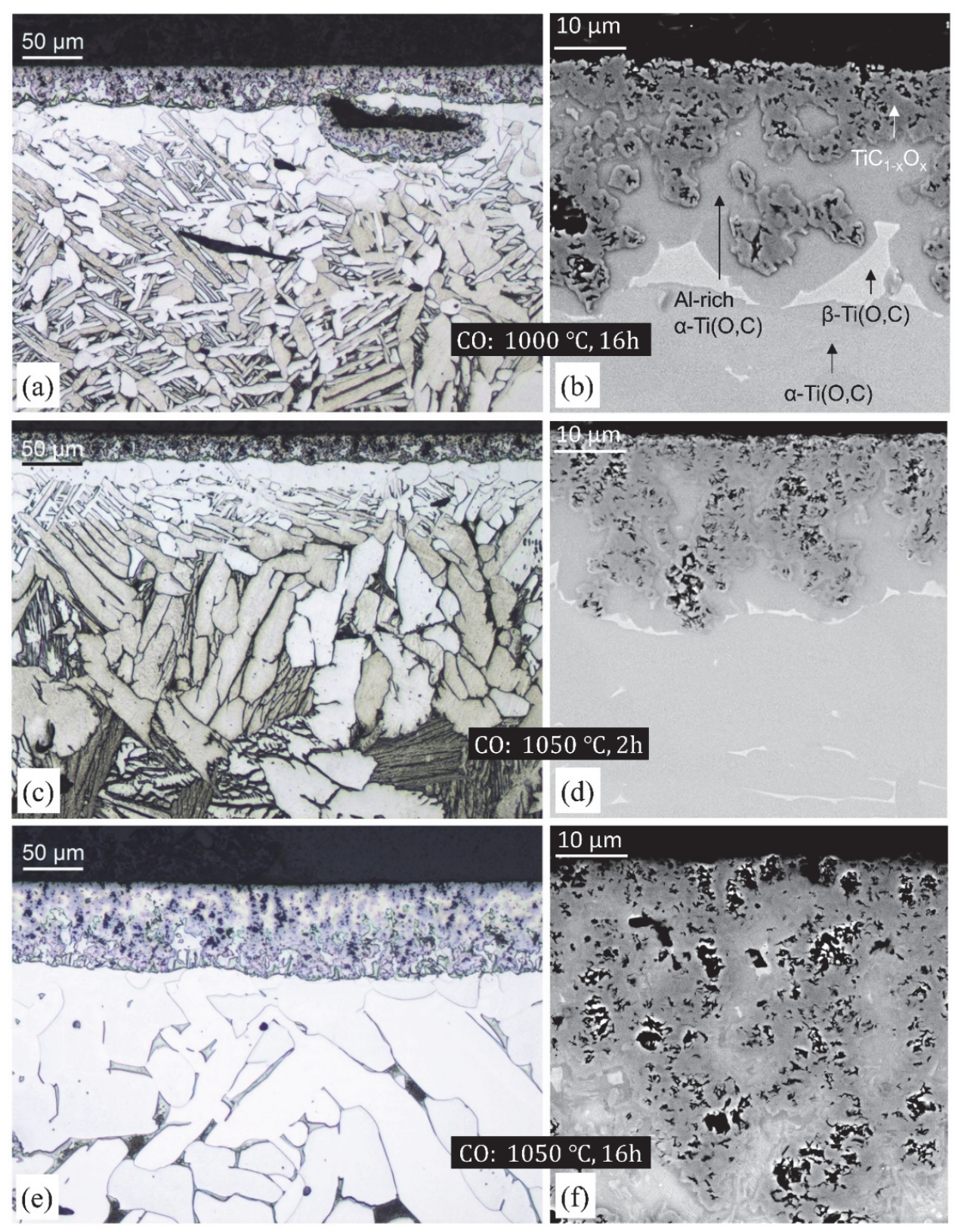

Figure 7: Light optical (a-c-e) and scanning electron (back-scatter detector) (b-d-f) micrographs of cross-sections of carbo-oxidised SLM Ti-6Al-4V samples, treated at (a-b) $1000^{\circ} \mathrm{C}$ for $16 \mathrm{~h},(\mathrm{c}-\mathrm{d}) 1050{ }^{\circ} \mathrm{C}$ for $2 \mathrm{~h}$ and (e-f) $1050{ }^{\circ} \mathrm{C}$ for $16 \mathrm{~h}$, in CO gas flow (ground surfaces). Etched with oxalic tinting reagent for 10 s for LOM (a-c-e), polished with OP-S for SEM (b-d-f).

The transformation of $\beta$ into $\alpha$ phase upon introducing oxygen is, as a consequence of the volume reduction, associated with the occurrence of tensile stress in the $\alpha$ phase (and small compensating compressive stresses in the $\beta$ phase). This can in principle lead to crack formation. Upon forming 
these cracks, the gas mixture penetrates into the cracks and leads to the incorporation of both $\mathrm{C}$ and $\mathrm{O}$, thereby promoting carbo-oxide formation. The ingress of $\mathrm{C}$ and $\mathrm{O}$ along cracks explains the long tongue-shaped protrusions of carbo-oxide into the $\alpha$ phase (Fig. 7b,d,f). In Figure 7(a), a pore, originating from the SLM process, is present in the near surface region and it is apparently interconnected with the surface and in contact with the gas atmosphere. Along the internal surface of the pore a compound zone has formed. Obviously, such features are unwanted in SLM parts.

Below the compound zone a thick diffusion zone consisting of expanded $\alpha$-Ti is observed. This manifests in LOM as white-etched regions, and is apparent just below the white $\beta$-regions in the BSE micrographs; in all three samples a gradual change into the two-phase zone is observed, evidenced by a decreasing amount of $\alpha$ phase. The bulk microstructure is located deeper in the sample than the depth range shown in the micrographs.

The $\alpha$-Ti grains stabilised by oxygen and carbon are larger after 16 hours treatment at $1050{ }^{\circ} \mathrm{C}$ as compared to the other treatments. This is a direct consequence of the prolonged treatment time and concomitant grain growth.

The relatively deep diffusion zones are reflected in the hardness profiles, shown in Figure 8. For the 16 hours $1050{ }^{\circ} \mathrm{C}$ sample, through-hardening occurred, so no unaffected bulk-material is present. The carbo-oxidising treatment resulted in a surface hardness of $1166 \pm 424 \mathrm{HV}_{0.01}$ and $1120 \pm 117 \mathrm{HV}_{0.01}(20 \mu \mathrm{m}$ from the surface $)$ after treatment for 16 hours at $1000{ }^{\circ} \mathrm{C}$ and 2 hours at $1050{ }^{\circ} \mathrm{C}$, respectively, which is well above those achieved by nitriding, or by nitriding followed by low temperature (carbo-)oxidising. The wide confidence intervals are caused by the heterogeneous distribution of the carbo-oxides. The transition from the hard carbo-oxide to the softer aluminium rich $\alpha$-matrix is sharp, but the carbo-oxide distribution is irregular (reflecting the evolving crack pattern on continued $\alpha$-phase formation followed by $\mathrm{CO}$ gas penetration). 
Consequently, measurements at the same depth can probe carbo-oxide $(\sim 1400 \mathrm{HV})$ and/or the Alrich $\alpha$-phase (800 HV).

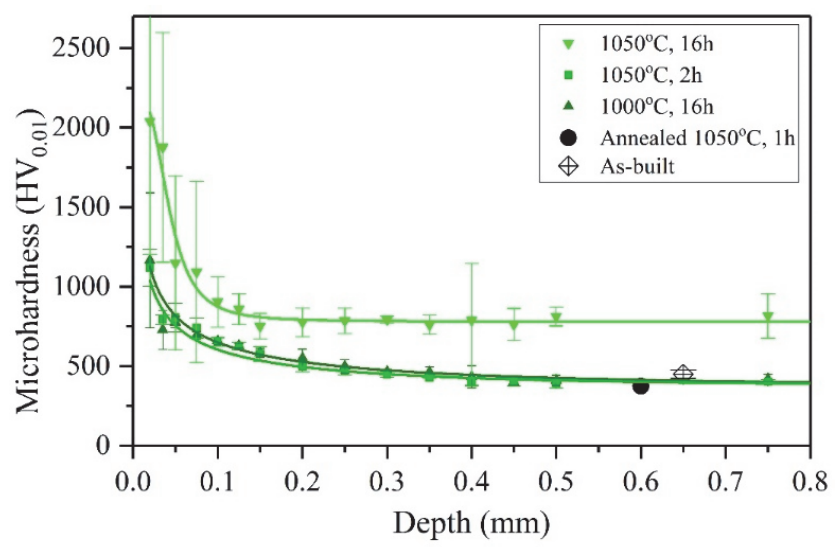

Figure 8: Micro-hardness profiles of carbo-oxidised SLM Ti-6Al-4V samples, treated in pure CO for different durations and temperatures. As reference, the average micro-hardness of as-built and annealed samples are included (see legends in figure). The curves are drawn to guide the eye.

The sample treated at $1050^{\circ} \mathrm{C}$ for 16 hours has a hardness of $2040 \pm 838 \mathrm{HV}_{0.01}$, which is largely explained by the relatively high amount of carbo-oxide in the surface-adjacent region, while the "softer" aluminium rich $\alpha$-matrix is now present deeper in the sample. Additionally, the increase in lattice spacing for the carbo-oxide as observed with XRD hints at a higher $\mathrm{C}$ to $\mathrm{O}$ ratio (and/or higher total interstitial content)[17], and thus higher hardness, as the TiC compound is significantly harder than $\mathrm{TiO}[6]$.

\subsection{Chemically controlled carbo-oxidising}

X-ray diffractograms of the chemically controlled carbo-oxidised samples are shown in Figure 9. Both oxides, mixed interstitial compounds and interstitially rich $\alpha$-Ti have formed. Treatment at $850{ }^{\circ} \mathrm{C}$ essentially results in a diffusion zone, i.e. $\mathrm{C}$ and $\mathrm{O}$ dissolved in $\alpha$-Ti. A small amount of $\beta$ is identified as a shoulder to the $101 \alpha$-Ti peak. Furthermore, minor peaks of carbo-oxide are identified. The lattice expansion in the diffusion zone, $\alpha-\operatorname{Ti}(\mathrm{O}, \mathrm{N})$, appears to increase with 
treatment temperature, which is interpreted as more oxygen and carbon dissolved in the HCP lattice for higher temperature. For the samples treated at $925^{\circ} \mathrm{C}$, and above, two sets of $\alpha$-Ti peaks are identified, analogous to carbo-oxidising in a $\mathrm{CO}$ atmosphere (cf. section 3.3). The intensity of both the carbo-oxide and the Al-rich $\alpha$-phase is low in the diffractogram for the sample treated at $925^{\circ} \mathrm{C}$, but increases with treatment temperature, corresponding to a thicker compound layer.

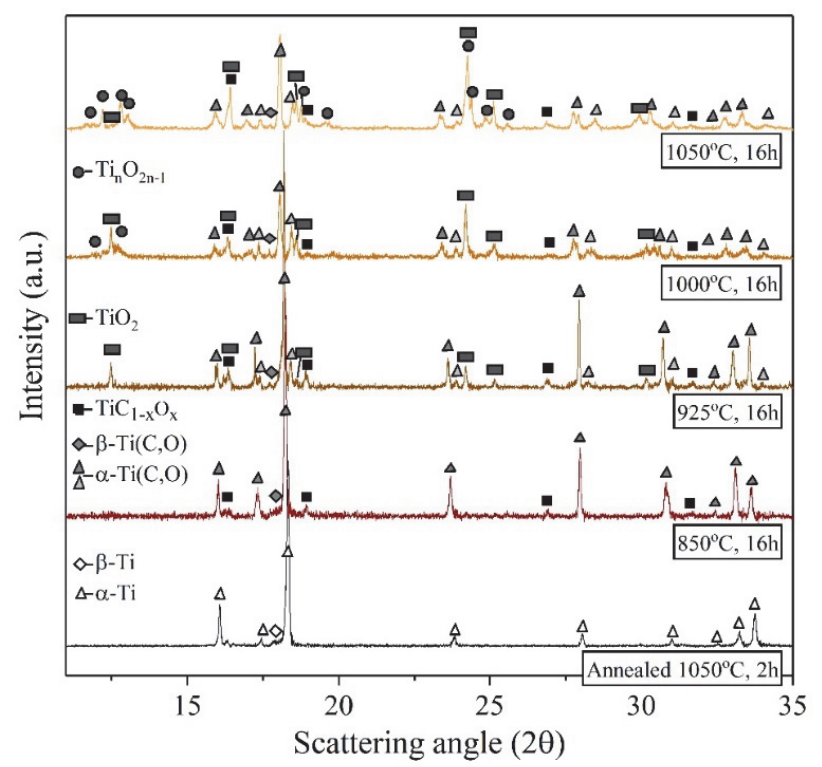

Figure 9: X-ray diffractograms of SLM Ti-6Al-4V following chemically controlled carbo-oxidising for 16 hours at different temperatures. As a reference, the diffractogram of an annealed and polished sample is included.

The higher oxygen partial pressure at $925{ }^{\circ} \mathrm{C}$ results in the formation of oxides. $\mathrm{TiO}_{2}$ can be identified at this temperature. At higher temperatures, also Magnéli phases were identified with XRD, mostly $\mathrm{Ti}_{9} \mathrm{O}_{17}$ and $\mathrm{Ti}_{6} \mathrm{O}_{11}$ phases.

Light optical micrographs of carbo-oxidised samples are shown in Figure 10. In the micrograph of the sample treated at $850{ }^{\circ} \mathrm{C}$ (Figure 10 (a)), mainly a diffusion zone of about $100 \mu \mathrm{m}$ thickness is observed, but also a thin carbo-oxide could be identified at higher magnifications (not shown). The diffusion zone has retained the morphology of the bulk structure, i.e. decomposed martensite that has coarsened into lamellar $\alpha-\beta$. The as-built martensitic structure ( $\left.\alpha^{\prime}\right)$ decomposes into $\alpha$ and $\beta$ 
upon heating; the fraction of $\beta$ increases with temperature. Also, partitioning of alloying elements takes place. Oxygen and carbon preferentially reside in the plates of $\alpha$-phase, i.e. the "stringers/plates" that appear white in the micrograph (Fig. 10a). For the sample treated at $925^{\circ} \mathrm{C}$, an approximately $30 \mu \mathrm{m}$ continuous $\alpha$-case below the thin compound layer is observed in the micrograph (Figure 10(b)). Below this continuous $\alpha$-case, a dispersed two-phase $\alpha$-zone is present, indicating a gradient in $\mathrm{C} / \mathrm{O}$. The thickness of the continuous $\alpha$-case significantly increases for the samples treated at $1000{ }^{\circ} \mathrm{C}$ and the grains become larger (Figure $10(\mathrm{c})$ ).
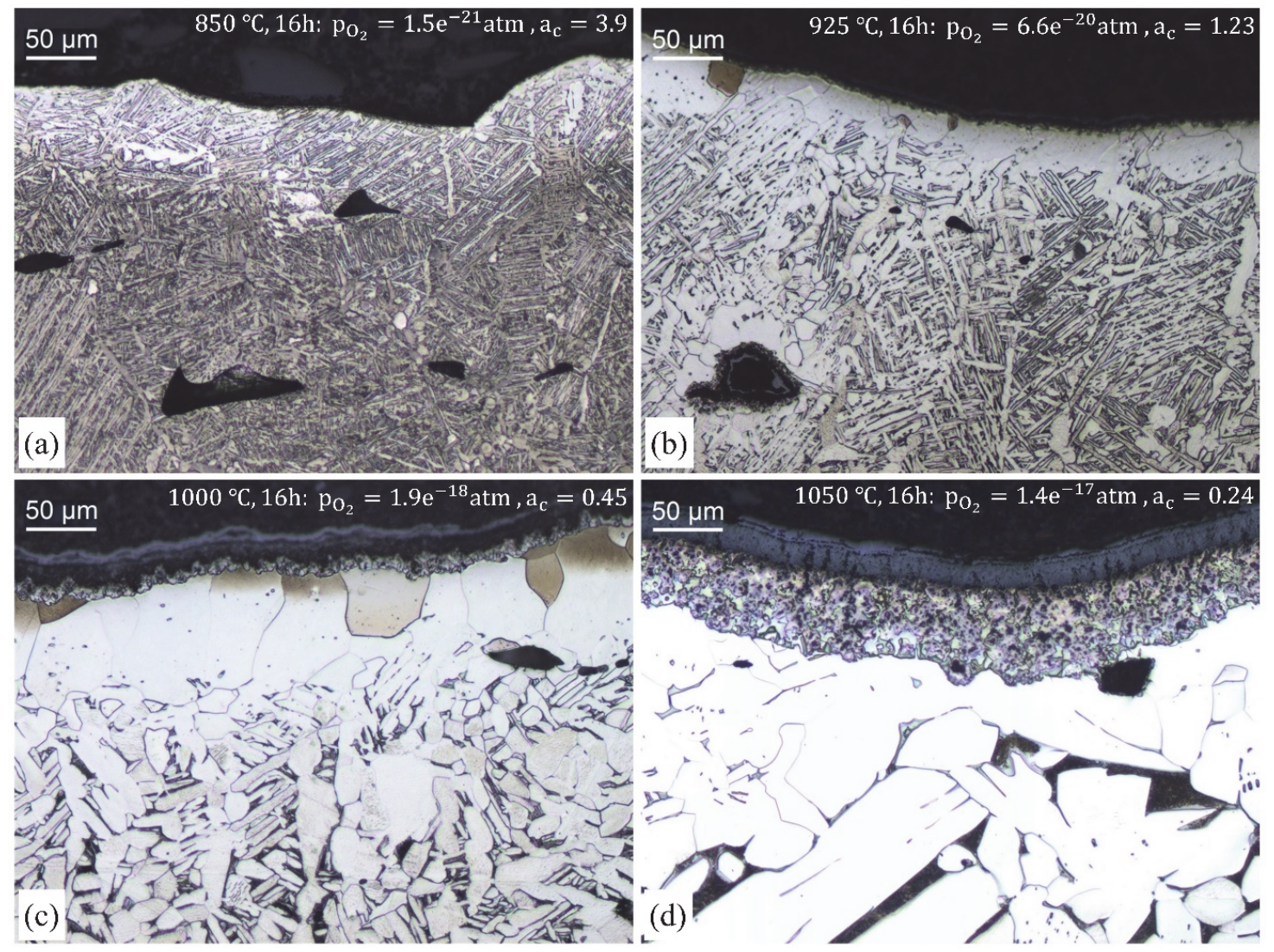

Figure 10: Light optical micrographs of cross-sections of the chemically controlled carbo-oxidised SLM Ti-6Al-4V samples, treated at (a) $850{ }^{\circ} \mathrm{C}$, (b) $925^{\circ} \mathrm{C}$, (c) $1000^{\circ} \mathrm{C}$ and (d) $1050^{\circ} \mathrm{C}$, for 16 hours in a $\mathrm{CO} / \mathrm{CO}_{2}$ gas mixture (asbuilt surfaces). Etched with oxalic tinting reagent for $10 \mathrm{~s}$.

The same trend applies for the $1050{ }^{\circ} \mathrm{C}$ sample, where the diffusion zone extends beyond the micrograph and massive grain growth has occurred (Figure 10(d)). The denser nature of the 
diffusion zone can be attributed to an increase in the interstitial content of the expanded $\alpha$ near the surface with increasing temperature. This is also consistent with the observed shift of the $\alpha-\operatorname{Ti}(\mathrm{C}, \mathrm{O})$ peaks in XRD towards lower $2 \theta$ angles (Figure 9). For the $1000^{\circ} \mathrm{C}$ and $1050^{\circ} \mathrm{C}$ treatments, also the thickness of the compound zone increases (Figure 10(c-d)). The compound layer was generally not uniform in the chemically controlled carbo-oxidised samples, as different microstructures and thicknesses were found at different locations. In the near surface region, above the compound layer, a thick, slightly porous stratified oxide layer is observed, which consists of rutile and Magnéli phases, as identified by XRD (Figure 10(c-d)).

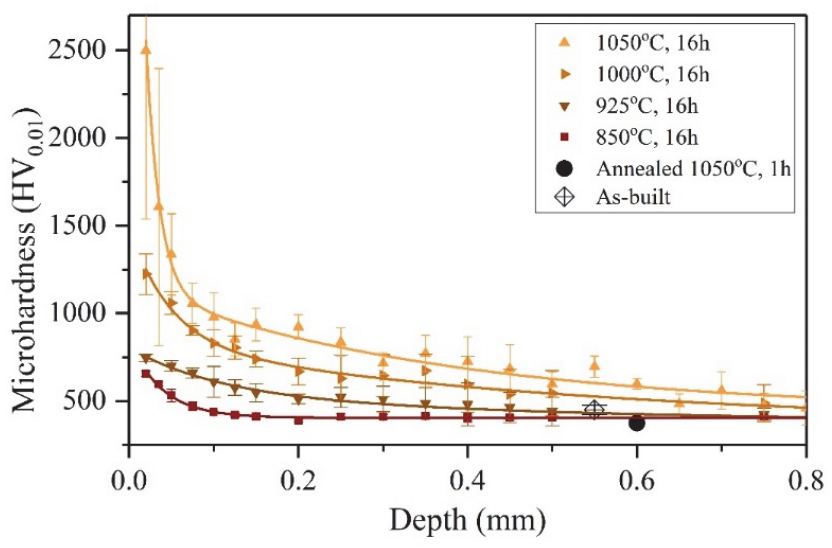

Figure 11: Micro-hardness profiles of chemically controlled carbo-oxidised SLM Ti-6Al-4V samples, treated for 16 hours at different temperatures. The average micro-hardness of as-built and annealed samples is included for comparison. The curves are drawn to guide the eye.

Hardness-depth profiles of the carbo-oxidised samples are given in Figure 11. The hardness at a depth of $20 \mu \mathrm{m}$ from the surface averaged $648 \pm 75 \mathrm{HV}_{0.01}, 747 \pm 20 \mathrm{HV}_{0.01}, 1224 \pm 116 \mathrm{HV}_{0.01}$ and $2498 \pm 961 \mathrm{HV}_{0.01}$, for the samples treated at $850{ }^{\circ} \mathrm{C}, 925{ }^{\circ} \mathrm{C}, 1000{ }^{\circ} \mathrm{C}$ and $1050{ }^{\circ} \mathrm{C}$, respectively. It should be noted, that due to the thick oxide layers, the measurements on some samples (in particular for the $1000{ }^{\circ} \mathrm{C}$ and $1050{ }^{\circ} \mathrm{C}$ samples) were obtained closer to the surface of the carbo-oxide layer, and sometimes within the oxide layer. This hinders a comparison of the carbo-oxides formed at the two different carbo-oxidising treatments, based on the hardness profile. 
The high hardness deviation for the sample treated at $1050{ }^{\circ} \mathrm{C}$, was also due to measurements obtained in different phases, i.e. oxide, at the oxide-carbo-oxide interphase, the softer matrix and at the hard carbo-oxides. The depth of the diffusion zone strongly increases with temperature. The same applies for the hardness in the diffusion zone; this indicates a higher interstitial content of carbon and/or oxygen at higher temperature. As for carbo-oxidising in $\mathrm{CO}$, a higher temperature results in a higher maximum hardness, consistent with higher amounts of carbo-oxide, higher total interstitial content and possibly higher $\mathrm{C}$ to $\mathrm{O}$ ratios at a higher temperature.

\subsection{Bulk microstructures}
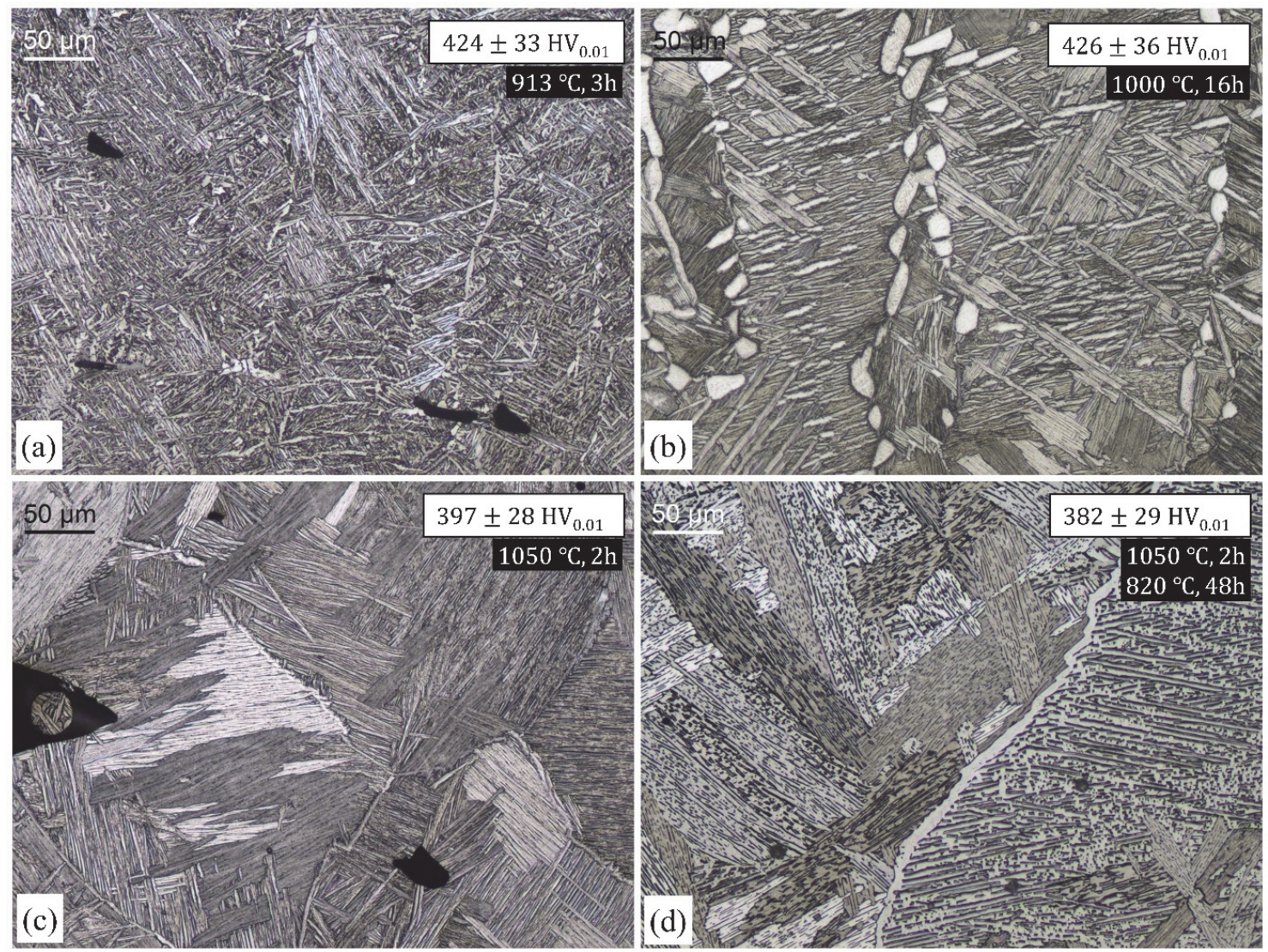

Figure 12: Light optical micrographs of cross-sections showing the bulk microstructures after surface treatments at: (a) $913{ }^{\circ} \mathrm{C}$ for $3 \mathrm{~h}$ with $30^{\circ} /$ min cooling, (b) $1000{ }^{\circ} \mathrm{C}$ for $16 \mathrm{~h}$ with $94^{\circ} /$ min cooling, (c) $1050{ }^{\circ} \mathrm{C}$ for $2 \mathrm{~h}$ with $94^{\circ} / \mathrm{min}$ 
cooling and (d) $1050^{\circ} \mathrm{C}$ for $2 \mathrm{~h}$ with $30^{\circ} /$ min cooling followed by $48 \mathrm{~h}$ at $820^{\circ} \mathrm{C}$ with furnace cooling, of SLM Ti-6Al$4 V$. Etched with oxalic tinting reagent for $10 \mathrm{~s}$.

All treatments resulted in a change of the bulk microstructure, because of the relatively high treatment temperatures. A treatment below the $\beta$-transus, e.g. at $913{ }^{\circ} \mathrm{C}$ for $3 \mathrm{~h}$, (Figure $12(\mathrm{a})$ ), resulted in the decomposition of $\alpha^{\prime}$ martensite into grain boundary and platelet $\alpha$ with intergranular $\beta$ (lamellar structure). The lath thickness of intergranular $\beta$ increases with treatment time and with temperature (not shown). Sallica-Leva et al. described the decomposition mechanism in SLM Ti6Al-4V as governed by nucleation and growth, where precipitation of $\beta$ at $\alpha^{\prime}$ lath boundaries leads to the gradual transformation of $\alpha$ ' into $\alpha$ by diffusion of the excess vanadium from the supersaturated $\alpha^{\prime}$.[19] The plates grew coarser with increasing treatment time and temperature, while the elongated shape of the prior $\beta$ grains was retained, as was previously described by Vrancken et al.[20].

Treatment at $913{ }^{\circ} \mathrm{C}$ for 3 hours followed by "gas cooling” (a thermal anneal specified by AMS 4999 for laser deposited Ti-6Al-4V) resulted in a hardness of $424 \mathrm{HV}_{0.01}$. For comparison, treatment at $850{ }^{\circ} \mathrm{C}$ and $925^{\circ} \mathrm{C}$ for 16 hours resulted in bulk hardness values of $408 \mathrm{HV}_{0.01}$ and $402 \mathrm{HV}_{0.01}$, respectively. Hence, only a marginal decrease in bulk hardness is observed. It should be mentioned that the cooling rate from the treatment temperature plays a significant role, as it governs the width of the $\alpha$ lamellae and the colony size.

Even though tempering of martensite in Ti-6Al-4V traditionally leads to an increase in hardness [21], the highest bulk hardness of $449 \mathrm{HV}_{0.01}$ was obtained for the as-built martensitic microstructure. Usually, martensite in Ti-6Al-4V has a lower strength than the strength obtained after precipitation of $\alpha$ and $\beta$ on tempering [21]. Vilaro et al. also observed a decrease in hardness following martensite decomposition, after tempering at $720^{\circ} \mathrm{C}$ for 2 hours [22], as did SallicaLeva et al. after both $650{ }^{\circ} \mathrm{C}$ for 2 hours and $800^{\circ} \mathrm{C}$ for 1 and 2 hours [19]. Both research groups attributed the hardness loss to partial $\alpha^{\prime}$ decomposition. Sallica-Leva et al. ascribed the high 
hardness in the as-built condition to the presence of fine needles, formed as a consequence of the high cooling rate, in combination with solid solution hardening of $\alpha$ supersaturated with vanadium.

In the present work, treatment at $1000^{\circ} \mathrm{C}$ resulted in elongated prior $\beta$ grains, large globular primary $\alpha$ grains at the boundaries of the prior $\beta$ grains and thick primary $\alpha$ plates starting to fragment (Figure 12(b)). Evidently, the heat treatment at $1000{ }^{\circ} \mathrm{C}$ for 16 hours did not fully transform the microstructure into $\beta$ phase. The significant $\beta$ fraction formed at the treatment temperature, decomposed into fine lamellar $\alpha / \beta$ during cooling. The hardness of $426 \mathrm{HV}_{0.01}$ is relatively high and comparable to the hardness after thermal anneal for $3 \mathrm{~h}$ at $913{ }^{\circ} \mathrm{C}$. The microstructure is close to the bi-modal structure typical for thermos-mechanical treatments [23]. Bi-modal structures offer improved ductility as compared to a lamellar structure (cooling from the $\beta$ range).

While the $\beta$ transus of the alloy is evidently above $1000^{\circ} \mathrm{C}$, for the actual alloy composition, 1050 ${ }^{\circ} \mathrm{C}$ is clearly above the $\beta$ transus temperature. This is evident from the Widmannstätten microstructure obtained after $2 \mathrm{~h}$ treatment at $1050{ }^{\circ} \mathrm{C}$ shown in Figure $12(\mathrm{c})$. The treatment above the $\beta$ transus annihilated the elongated as-printed morphology, and created fine $\alpha$-Widmannstätten colonies in the large prior $\beta$ grains with small amounts of grain boundary $\alpha$, thus reducing the hardness to $397 \mathrm{HV}_{0.01}$

Figure 12(d) shows the microstructure formed after annealing for 48 hours at $820^{\circ} \mathrm{C}$ subsequent to treatment at $1050{ }^{\circ} \mathrm{C}$. The two-day anneal of the Widmannstätten microstructure resulted in incomplete spheroidisation, where solute diffusion from the lamella edge to the flat surfaces resulted in the recession of the platelet edges [24-26], here resulting in a coarsening of both $\alpha$ and $\beta$ lamellae, accompanied by $\beta$ platelet breakup. The coarsening leads to a decrease in hardness to $382 \mathrm{HV}_{0.01}$, which is only $15 \mathrm{HV}$ lower than after the $\beta$ anneal at $1050{ }^{\circ} \mathrm{C}$ for $2 \mathrm{~h}$. 
The hardness of the bulk microstructures is high in general, and together with the high $\beta$ transus temperature, it is hypothesised that this is a consequence of an oxygen content higher than specified by ASTM F2924 $(<0.2 \mathrm{wt} \%)$. This additional oxygen could have dissolved during SLM processing.

\subsection{Wear testing}

To investigate the influence of thermochemical treatment on the tribological properties of SLM fabricated Ti-6Al-4V, three treatments were selected for wear testing. The thermochemical treatments were carried out on as-built samples ground to P4000 and compared to an annealed and ground reference SLM Ti-6Al-4V. Nitriding for $16 \mathrm{~h}$ at $1000{ }^{\circ} \mathrm{C}$, duplex nitriding and (carbo)oxidising and carbo-oxidising in $\mathrm{CO}$ for 16 hours at $1000{ }^{\circ} \mathrm{C}$ were chosen, because of their promising hardness profiles and different layer compositions. The roughness of the surfaces was measured on the selected samples prior to wear testing. The roughness of the annealed and ground specimen was $\mathrm{R}_{\mathrm{a}}=0.6 \pm 0.3 \mu \mathrm{m}$, which increased to $\mathrm{R}_{\mathrm{a}}=1.1 \pm 0.4 \mu \mathrm{m}$ by the nitriding treatment, similar to the roughness increase Sarro et al. observed after gaseous nitriding [27].

Contrary to nitriding, carbo-oxidising had no -or a positive effect- on the roughness of the ground Ti-6Al-4V surface, as the roughness after the duplex nitriding and (carbo-)oxidising was reduced insignificantly to $R_{a}=0.5 \pm 0.1 \mu \mathrm{m}$, while carbo-oxidising resulted in a roughness of $R_{a}=0.6 \pm$ $0.1 \mu \mathrm{m}$, similar to the reference sample (annealed and ground).

The selected samples were tested by reciprocating pin-on-disc test against $\mathrm{Al}_{2} \mathrm{O}_{3}$ balls, and the resulting friction coefficient curves of the four specimens are shown in Figure 13. $\mathrm{Al}_{2} \mathrm{O}_{3}$ were chosen in order to minimise the counterbody wear, by matching the high hardness of the specimens exposed to thermochemical treatments. The friction coefficient $(\mu)$ of the annealed "reference" sample averaged 0.45 and fluctuated around the same level throughout the test. The irregular 
fluctuations are typical of adhesive wear, which was confirmed by SEM of the wear track, shown in Figure 14(a). The rough areas and craters indicate adhesive wear, while the grooves are typical of abrasive wear, showing that the sample experienced mixed wear.

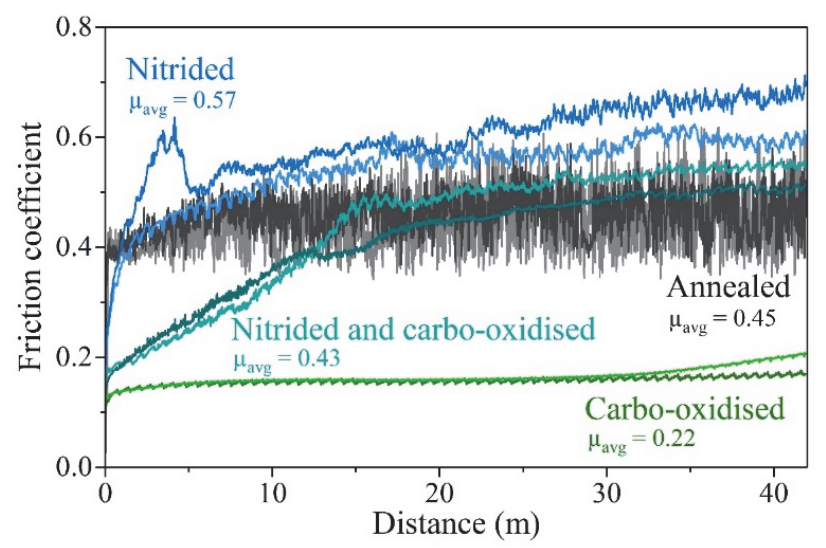

Figure 13: Friction coefficient during pin on disc wear testing, between the $\mathrm{Al}_{2} \mathrm{O}_{3}$ pin and the ground SLM Ti-6Al-4V samples subjected to different treatments: Annealed $\left(1050^{\circ} \mathrm{C}, 1 \mathrm{~h}\right.$, prior to grinding), nitrided $\left(1000^{\circ} \mathrm{C}, 16 \mathrm{~h}\right)$, nitrided and (carbo-) oxidised $\left(1050^{\circ} \mathrm{C}, 2 \mathrm{~h}+820^{\circ} \mathrm{C}, 48 \mathrm{~h}\right)$ and carbo-oxidised $\left(1000^{\circ} \mathrm{C}, 16 \mathrm{~h}\right.$ in CO). Two tests were performed on each specimen, and dark and bright lines represent the first and second test, respectively.

The friction coefficient of the nitrided sample increases after initial running-in wear and then stabilises around $\mu=0.6$, i.e. higher than for the annealed sample.

The wear track, shown in Figure 14(b), is smooth, showing how the $\mathrm{Al}_{2} \mathrm{O}_{3}$ ball polished the rough TiN structure. Backscatter electron (BSE) imaging (right side of Figure 14(b)), shows bright areas which are interpreted as regions with less nitrogen than TiN. This indicates that locally, at asperities, the wear track has reached the $\mathrm{Ti}_{2} \mathrm{~N}$ layer.

The friction coefficient curves of the nitrided and carbo-oxidised sample starts at a low value similar to the nitrided specimen, but increases steadily until around $15 \mathrm{~m}$, where it shifts into a modest increase ending just slightly higher than the annealed reference sample. This abrupt change could be caused by a run-out of a "low-friction" phase, most likely a Magnéli-type phase. The 
wear track in SEM (Figure 14(c)) appears consistent with the interpretation of removal of an outer phase; BSE imaging shows a bright wear track. Combining the observation in the wear track in Fig. 15(c) with the evolution of the friction coefficient in Fig. 14c, the slow increase in the second part of the curve is interpreted as wear of the zone underneath the Magnéli phase, i.e. the $\mathrm{TiC}_{1-\mathrm{x} \text { - }}$ y $\mathrm{N}_{\mathrm{x}} \mathrm{O}_{\mathrm{y}}$ phase.
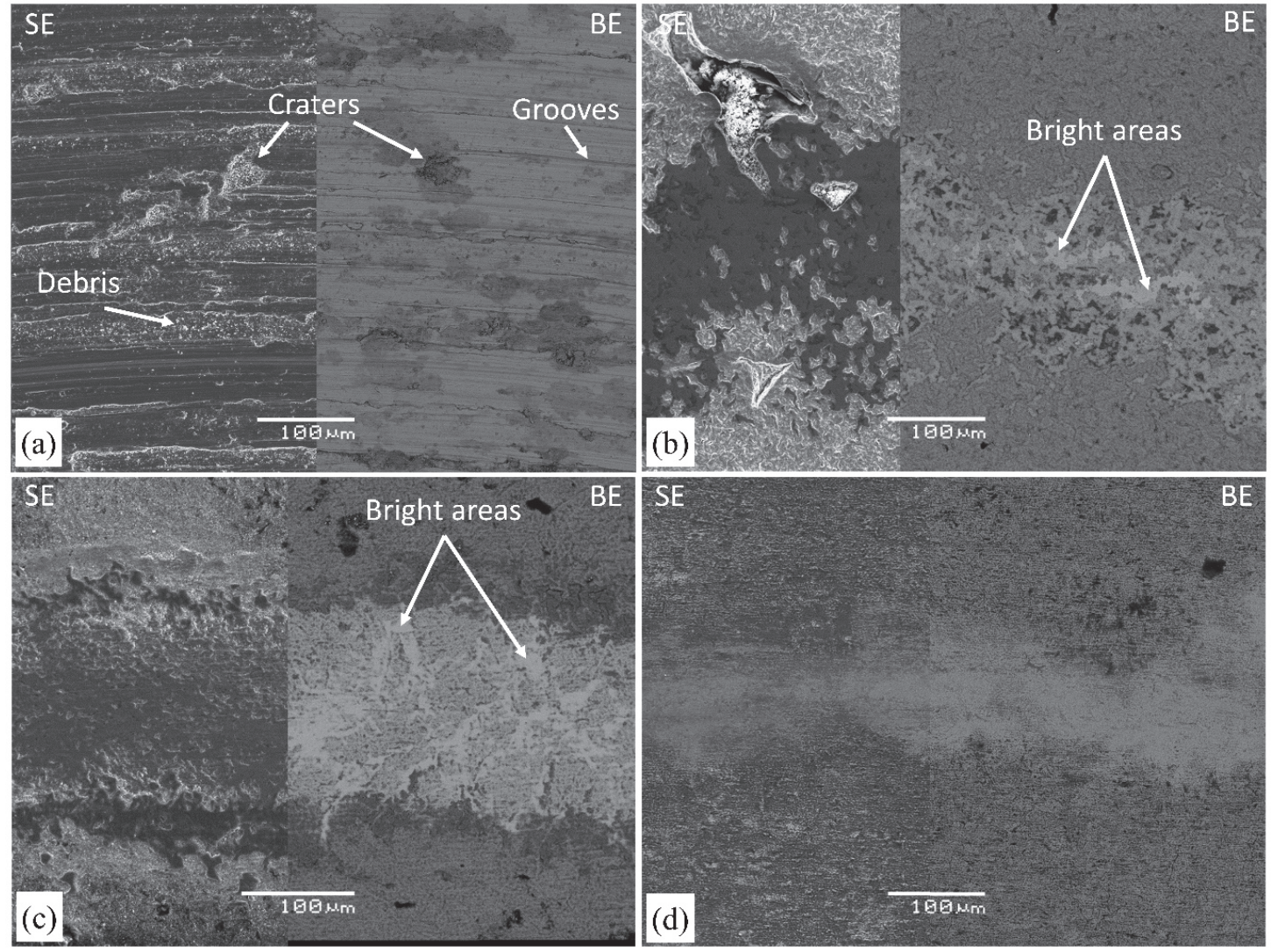

Figure 14: Secondary electron (SE; left side) and Backscatter electron (BSE; right side) micrographs of the wear tracks of ground and (a) annealed (prior to grinding), (b) nitrided, (c) nitrided and (carbo-)oxidised and (d) carbooxidised SLM Ti-6Al-4V samples.

The friction coefficient of the carbo-oxidised sample starts around 0.12 , and after an initial small increase, it stays low and stable at 0.16 until $35-40 \mathrm{~m}$, where it slightly increases. This could indicate that the sliding occurred in the same layer, $\mathrm{TiC}_{1-\mathrm{x}} \mathrm{O}_{\mathrm{x}}$, throughout the duration of the test, 
and started to break through or run out of lubricating material towards the end. Figure 14(d) corroborates this as the small wear track appears smooth with no visible composition variations.

Figure 15 shows the specific wear volume of the four specimens, which was calculated from the width of the wear scars as measured with $\mathrm{LOM}$ (wear on the $\mathrm{Al}_{2} \mathrm{O}_{3}$ was negligible). All treatments lead to significant improvement in wear resistance, as the total wear volume of all the thermochemically-hardened samples was significantly reduced. As compared to the annealed SLM Ti-6Al-4V sample, the wear volume was reduced by roughly 200, 300 and 450 times, for nitriding, duplex nitriding/(carbo-)oxidising and carbo-oxidising, respectively.

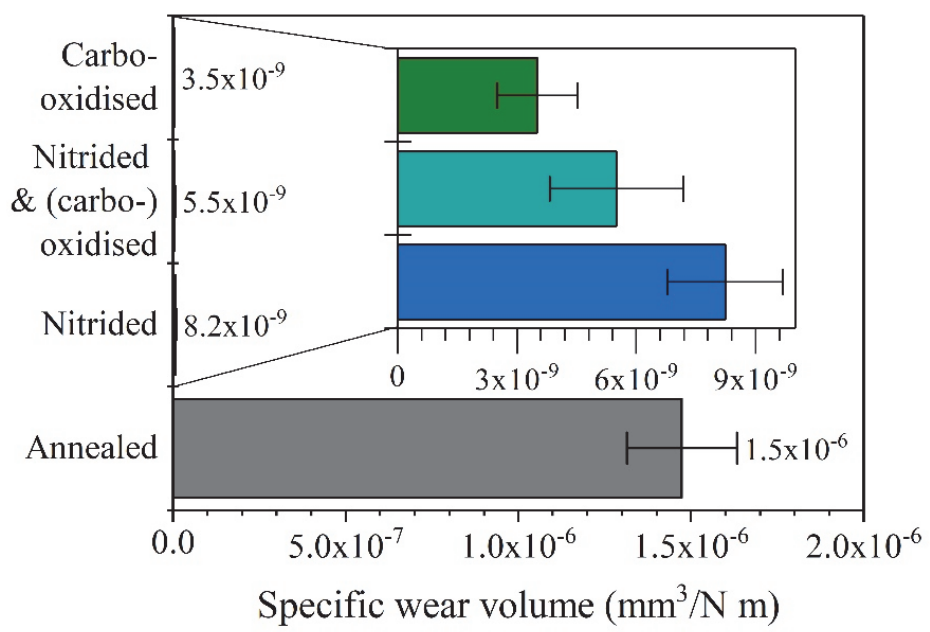

Figure 15: Specific wear volume of carbo-oxidised $\left(100{ }^{\circ} \mathrm{C}, 16 \mathrm{~h}\right.$ in CO), nitrided/ (carbo-)oxidised $\left(1050{ }^{\circ} \mathrm{C}, 2 \mathrm{~h}+\right.$ $\left.820^{\circ} \mathrm{C}, 48 \mathrm{~h}\right)$, nitrided $\left(1000^{\circ} \mathrm{C}, 16 \mathrm{~h}\right)$ and annealed $\left(1050^{\circ} \mathrm{C}, \mathrm{h}\right)$ samples.

\subsection{Surface engineering of SLM Ti-6Al-4V}

Comparing carbo-oxidising in $\mathrm{CO}$ with chemically controlled carbo-oxidising for the $1000{ }^{\circ} \mathrm{C}$ and $1050{ }^{\circ} \mathrm{C}$ for 16 hours treatment, a higher hardness is achieved for the specimen treated under chemical control of the gas atmosphere, albeit with a much larger variation in hardness. The through-hardening of the $\mathrm{CO}$ carbo-oxidising treatment at $1050{ }^{\circ} \mathrm{C}$ for 16 hours demonstrates faster hardening of carbo-oxidising in $\mathrm{CO}$ as compared to the chemically controlled treatment with 
higher po2. This illustrates that there is a significant difference in the surface layers that have formed. Evidently, the diffusion of carbon and oxygen into the bulk is slowed down at the higher pO2. This may be due to the formation of oxides at the surface or different types of compounds that have formed in the case. Due to the more homogeneous surface layer obtained after CO carbooxidising, this process was preferred over the treatments with chemically controlled carbooxidising, despite the evident advantage of process control obtained by chemically controlled carbo-oxidising.

The lowest wear volume was achieved for the carbo-oxidised sample, which was the only specimen that exhibits a lower friction coefficient than the reference sample throughout the entire test. Hence, this variant is considered an excellent candidate for surface engineering of SLM Ti$6 \mathrm{Al}-4 \mathrm{~V}$, if improved wear resistance is required. Since carbo-oxidising in $\mathrm{CO}$ at $1000{ }^{\circ} \mathrm{C}$ for 16 hours resulted in a thick, porous and uniform layer of titanium carbo-oxide, which was not worn through, the low friction coefficient and high wear resistance are ascribed to the hard carbo-oxide layer. The excellent wear properties of the carbo-oxide layer is explained by the mixed interstitial compounds having improved wear resistance compared to the binary compounds [6].

The low wear volume of the nitrided $\left(1000{ }^{\circ} \mathrm{C}\right.$ for $\left.16 \mathrm{~h}\right)$ SLM Ti-6Al-4V specimen also makes this treatment a possible candidate for improved wear resistance of SLM Ti-6Al-4V. Conversely, the high friction coefficient is unwanted in most applications, although the friction coefficient depends highly on the counter body together with load, surface roughness and lubrication. The friction coefficient of TiN as reported in the literature [4] varies significantly. Even though a friction coefficient of 0.56 , as exhibited by the nitrided SLM Ti-6Al-4V, appears high, this value is not uncommon for TiN tested under dry conditions [28].

Combined nitriding $\left(1050^{\circ} \mathrm{C}\right.$ for $\left.2 \mathrm{~h}\right)$ and (carbo-)oxidising $\left(820^{\circ} \mathrm{C}\right.$ for $\left.48 \mathrm{~h}\right)$ resulted in reduction of the wear volume and of the friction coefficient, as compared to nitriding $\left(100{ }^{\circ} \mathrm{C}\right.$ for $\left.16 \mathrm{~h}\right)$. As 
the hardness profiles measured after the two treatments are comparable, the difference in wear performance is attributed to the different phases formed during the treatments. In particular the transformation of the nitride layer into an oxy-nitride and the formation of a thin Magnéli phase layer after (carbo-)oxidising at $820^{\circ} \mathrm{C}$ for $48 \mathrm{~h}$ are anticipated to improve the wear performance significantly.

The formation and exploitation of Magnéli phases has previously been investigated because of their excellent wear resistance [29]. Most of the published work relates to pure powders or rutile powder as a starting material. Gardos postulated lower friction of Magnéli phases [30], while Woydt, investigating sintered Magnéli powders, found improvement in wear resistance rather than lubricating performance [31]. In the present work, wear testing was also performed on a sample with a thick layer of Magnéli phase, obtained after chemically controlled carbo-oxidising at 1050 ${ }^{\circ} \mathrm{C}$ for $16 \mathrm{~h}$, leading to the microstructure shown in Figure $10(\mathrm{c})$. Friction coefficients of $\mu=0.6$ were obtained. More investigations should be performed to explain the different wear properties observed for the Magnéli phases formed by different thermochemical treatments.

Nevertheless, the wear results obtained on SLM Ti-6Al-4V (carbo-)oxidised at a temperature and oxygen partial pressure allowing the formation of a thin Magnéli layer $\left(820^{\circ} \mathrm{C}\right.$ for $\left.48 \mathrm{~h}\right)$ indicates a large potential for thermochemical Magnéli for the improvement of wear performance. Moreover, the formation of the ternary and quaternary Ti-C-N-O compounds by thermochemical treatment has shown great improvement in the wear properties of SLM Ti-6Al-4V, regarding both wear rate and friction coefficient.

In general, thermochemical treatments are a viable means to engineer the surface of titanium AM components, as the treatment allows uniform treatment of all surfaces (not just line-of-sight), and leads to comparable results on ground and as-built surfaces. Heat treatment is already a necessity for most Ti-6Al-4V AM parts, and the present work clearly shows the possibilities to expand the 
heat treatment process to a surface treatment, when improved wear resistance is required. Obviously, the thermochemical treatment should be carefully tailored to provide a combination of an appropriate heat treatment and thermochemical treatment, yielding the desired hardness profile and favourable phases, for the intended applications of the part.

\section{Conclusion}

Surface hardening of SLM fabricated Ti-6Al-4V was obtained by different gaseous thermochemical treatments, both on as-built surfaces and on ground surfaces for wear investigations.

Nitriding resulted in the formation of a diffusion zone and a uniform compound layer, consisting of TiN after 2 hours at $1050{ }^{\circ} \mathrm{C}$, and TiN and Ti2 $\mathrm{N}$ after 16 hours at $1000^{\circ} \mathrm{C}$. An Al-rich $\alpha$-Ti zone was found below the compound zone. Carbo-oxidising in CO resulted in deep diffusion zones and thick compound layers of type $\mathrm{TiC}_{1-\mathrm{x}} \mathrm{O}_{\mathrm{x}}$. Also here, an $\mathrm{Al}$ rich $\alpha$-Ti phase was found below as well as surrounding the carbo-oxide phase. Similar microstructural features were observed after chemically controlled carbo-oxidising in $\mathrm{CO}-\mathrm{CO}_{2}$ gas mixtures, albeit with thinner and nonuniform compound layers/zones. In addition, oxides formed at the surface on top of the compound layer. For both types of carbo-oxidising treatments, the diffusion zone and compound layer increased with increasing treatment time and temperature. For the chemically controlled carbooxidising treatments, a higher temperature led to a thicker oxide layer, which transformed from rutile to Magnéli phase. All treatments resulted in a gradual decrease in hardness from the surface to the bulk; the highest surface hardness was measured at approx. $20 \mu \mathrm{m}$ from the surface. Chemically controlled carbo-oxidising at $1050{ }^{\circ} \mathrm{C}$ for $16 \mathrm{~h}$ resulted in a hardness value as high as $2498 \mathrm{HV}$; a value of $2040 \mathrm{HV}$ was obtained after treatment in pure CO. Nitriding followed by carbo-oxidising at $820{ }^{\circ} \mathrm{C}$ resulted in a transformation of the TiN compound layer into a mixed interstitial $\mathrm{TiC}_{1-\mathrm{x}-\mathrm{y}} \mathrm{N}_{\mathrm{x}} \mathrm{O}_{\mathrm{y}}$ and formation of a $\mathrm{Ti}_{2} \mathrm{~N}$ layer. 
As a consequence of the elevated temperatures, all thermochemical treatments resulted in an altered core microstructure, where martensite was transformed into lamellar $\alpha$ and $\beta$ of different morphologies.

The three most promising treatments were tested in dry sliding friction against $\mathrm{Al}_{2} \mathrm{O}_{3}$. A significant reduction in specific wear volume was achieved for all three treatments. The most spectacular reduction, by up to 450 times, was measured after carbo-oxidising. Nitriding followed by carbooxidising resulted in low friction coefficient during initial running-in wear, while carbo-oxidising in CO significantly improved the friction coefficient throughout the test, reducing the average friction coefficient from 0.45 to 0.16 , for the relatively thick carbo-oxide layer.

\section{Acknowledgement}

The authors would like to acknowledge Carsten Gundlach and the imaging centre at DTU for performing the CT-scan. We also wish to acknowledge Jeppe Skinnerup Byskov and Lasse HaahrLillevang from the Danish Technological Institute in Aarhus for providing the SLM manufactured specimens subjected to the present investigations. This research did not receive any specific grant from funding agencies in the public, commercial, or not-for-profit sectors. 


\section{References}

[1] W.E. Frazier, Metal additive manufacturing: A review, in: J. Mater. Eng. Perform., Springer US, 2014: pp. 1917-1928. doi:10.1007/s11665-014-0958-z.

[2] B. Dutta, F.H. Froes, The Additive Manufacturing of Titanium Alloys, in: Addit. Manuf. Titan. Alloy., Elsevier, 2016: pp. 1-10. doi:10.1016/B978-0-12-804782-8.00001-X.

[3] A. Zhecheva, W. Sha, S. Malinov, A. Long, Enhancing the microstructure and properties of titanium alloys through nitriding and other surface engineering methods, Surf. Coatings Technol. 200 (2005) 2192-2207. doi:10.1016/J.SURFCOAT.2004.07.115.

[4] B. Sarma, K.S. Ravi Chandran, Recent advances in surface hardening of titanium, JOM. 63 (2011) 85-92. doi:10.1007/s11837-011-0035-0.

[5] H. Dong, X.Y. Li, Oxygen boost diffusion for the deep-case hardening of titanium alloys, Mater. Sci. Eng. A. 280 (2000) 303-310. doi:10.1016/S0921-5093(99)00697-8.

[6] V.M. Fedirko, I.M. Pohrelyuk, O.I. Yas'Kiv, Formation of functional coatings based on interstitial compounds on titanium under the conditions of thermodiffusion saturation, Mater. Sci. 42 (2006) 299-308. doi:10.1007/s11003-006-0083-8.

[7] O. Yaskiv, I. Pohrelyuk, D.-B. Lee, V. Fedirko, S. Guryn, Carbo-oxidising of titanium by diffusion treatment in carbon-oxygen containing media, Int. Heat Treat. Surf. Eng. 6 (2012) 72-79. doi:10.1179/1749514812Z.00000000023.

[8] N. Gammeltoft-Hansen, S.S. Munch, M.S. Jellesen, M.A.J. Somers, T.L. Christiansen, Characterization of Thermochemically Surface-Hardened Titanium by Light Optical Microscopy, Mater. Perform. Charact. 6 (2017) 20160083. doi:10.1520/MPC20160083.

[9] T.L. Christiansen, M.S. Jellesen, M.A.J. Somers, Future trends in gaseous surface hardening of titanium and titanium alloys, La Metall. Ital. 9 (2018) 13-22.

[10] P. Franz, A. Mukhtar, W. Downing, G. Smith, B. Jackson, Mechanical Behaviour of Gas Nitrided Ti6Al4V Bars Produced by Selective Laser Melting, Key Eng. Mater. 704 (2016) 225-234. doi:10.4028/www.scientific.net/KEM.704.225.

[11] H.K. Kim, H.G. Kim, B.-S. Lee, S.-H. Min, T.K. Ha, K.-H. Jung, C.-W. Lee, H.-K. Park, Atmosphere Gas Carburizing for Improved Wear Resistance of Pure Titanium Fabricated by Additive Manufacturing, Mater. Trans. $58 \quad$ (2017) 592-595. doi:10.2320/matertrans.M2016361.

[12] W.H. Kao, Y.L. Su, J.H. Horng, C.Y. Chang, Tribological, electrochemical and biocompatibility properties of Ti6Al4V alloy produced by selective laser melting method and then processed using gas nitriding, $\mathrm{CN}$ or Ti-C:H coating treatments, Surf. Coatings Technol. 350 (2018) 172-187. doi:10.1016/j.surfcoat.2018.07.011.

[13] T.L. Christiansen, M.S. Jellesen, M.A.J. Somers, N.B. Gammeltoft-Hansen, A case hardened component of titanium, Patent No.: WO2017207794. Dec 07, 2017.

[14] J. Yang, H. Yu, J. Yin, M. Gao, Z. Wang, X. Zeng, Formation and control of martensite in 
Ti-6Al-4V alloy produced by selective laser melting, Mater. Des. 108 (2016) 308-318. doi:10.1016/j.matdes.2016.06.117.

[15] L. Thijs, F. Verhaeghe, T. Craeghs, J. Van Humbeeck, J.-P. Kruth, A Study of the Microstructural Evolution During Selective Laser Melting of Ti-6Al-4V, Acta Mater. 58 (2010) 3303-3312. doi:10.1016/j.actamat.2010.02.004.

[16] Y. Xu, Y. Lu, K.L. Sundberg, J. Liang, R.D. Sisson, Effect of Annealing Treatments on the Microstructure, Mechanical Properties and Corrosion Behavior of Direct Metal Laser Sintered Ti-6Al-4V, J. Mater. Eng. Perform. 26 (2017) 2572-2582. doi:10.1007/s11665017-2710-y.

[17] B. Jiang, N. Hou, S. Huang, G. Zhou, J. Hou, Z. Cao, H. Zhu, Structural studies of TiC1$\mathrm{xOx}$ solid solution by Rietveld refinement and first-principles calculations, J. Solid State Chem. 204 (2013) 1-8. doi:10.1016/j.jssc.2013.05.009.

[18] W. Rostoker, Observations on the Lattice Parameters of the Alpha Solid Solution in the Titanium-Aluminum System, Jom. 4 (1952) 212-213. doi:10.1007/bf03397677.

[19] E. Sallica-Leva, R. Caram, A.L. Jardini, J.B. Fogagnolo, Ductility improvement due to martensite $\alpha^{\prime}$ decomposition in porous Ti-6Al-4V parts produced by selective laser melting for orthopedic implants, J. Mech. Behav. Biomed. Mater. 54 (2016) 149-158. doi:10.1016/j.jmbbm.2015.09.020.

[20] B. Vrancken, L. Thijs, J.-P. Kruth, J. Van Humbeeck, Heat treatment of Ti6Al4V produced by Selective Laser Melting: Microstructure and mechanical properties, J. Alloys Compd. 541 (2012) 177-185. doi:10.1016/j.jallcom.2012.07.022.

[21] F.X. Gil Mur, D. Rodríguez, J. a. Planell, Influence of tempering temperature and time on the $\alpha^{\prime}-$ Ti-6Al-4V martensite, J. Alloys Compd. 234 (1996) 287-289. doi:10.1016/09258388(95)02057-8.

[22] T. Vilaro, C. Colin, J.D. Bartout, As-fabricated and heat-treated microstructures of the Ti6Al-4V alloy processed by selective laser melting, Metall. Mater. Trans. A Phys. Metall. Mater. Sci. 42 (2011) 3190-3199. doi:10.1007/s11661-011-0731-y.

[23] M. Peters, G. Lütjering, G. Ziegler, Control of Microstructures of ( $\alpha+\beta)$-Titanium Alloys, Z. Met. 74 (1983) 274-282.

[24] Y.L. Tian, R.W. Kraft, Mechanisms of Pearlite Spheroidization, Metall. Trans. A. 18 (1987) 1403-1414. doi:10.1007/BF02646654.

[25] S. Zherebtsov, M. Murzinova, G. Salishchev, S.L. Semiatin, Spheroidization of the lamellar microstructure in Ti-6Al-4V alloy during warm deformation and annealing, Acta Mater. 59 (2011) 4138-4150. doi:10.1016/j.actamat.2011.03.037.

[26] Y.G. Nakagawa, G.C. Weatherly, E. Ho, Coarsening of Lamellar Structures at Elevated Temperatures, Trans. Japan Inst. Met. $15 \quad$ (1974) 114-120. doi:10.2320/matertrans 1960.15 .114 .

[27] M.I. Sarro, D.A. Moreno, C. Ranninger, E. King, J. Ruiz, Influence of gas nitriding of 
Ti6Al4V alloy at high temperature on the adhesion of Staphylococcus aureus, Surf. Coatings Technol. 201 (2006) 2807-2812. doi:10.1016/j.surfcoat.2006.05.023.

[28] Y.C. Lin, H.M. Chen, Y.C. Chen, The effect of different methods to add nitrogen to titanium alloys on the properties of titanium nitride clad layers, Mater. Des. 54 (2014) 222-229. doi:10.1016/j.matdes.2013.08.069.

[29] R. Bailey, Y. Sun, Unlubricated sliding friction and wear characteristics of thermally oxidized commercially pure titanium, Wear. 308 (2013) 61-70. doi:10.1016/j.wear.2013.09.020.

[30] M.N. Gardos, Magnéli phases of anion-deficient rutile as lubricious oxides. Part II. Tribological behavior of single-crystal and polycrystalline rutile, Tribol. Lett. 8 (2000) 6578. doi:10.1002/andp.200410099.

[31] M. Woydt, Tribological characteristics of polycrystalline Magnéli-type titanium dioxides, Tribol. Lett. 8 (2000) 117-130. doi:10.1023/A:1019170831371. 